\title{
The impact of P-gp functionality on non-steady state relationships between CSF and brain extracellular fluid
}

\author{
Joost Westerhout · Jean Smeets • Meindert Danhof • \\ Elizabeth C. M. de Lange
}

Received: 12 October 2012/ Accepted: 19 March 2013/Published online: 29 March 2013

(C) The Author(s) 2013. This article is published with open access at Springerlink.com

\begin{abstract}
In the development of central nervous system (CNS)-targeted drugs, the prediction of human CNS target exposure is a big challenge. Cerebrospinal fluid (CSF) concentrations have often been suggested as a 'good enough' surrogate for brain extracellular fluid (brain ${ }_{\mathrm{ECF}}$, brain target site) concentrations in humans. However, brain anatomy and physiology indicates prudence. We have applied a multiple microdialysis probe approach in rats, for continuous measurement and direct comparison of quinidine kinetics in brain ${ }_{\mathrm{ECF}}$, $\mathrm{CSF}$, and plasma. The data obtained indicated important differences between brain ${ }_{\mathrm{ECF}}$ and CSF kinetics, with brain ${ }_{\mathrm{ECF}}$ kinetics being most sensitive to P-gp inhibition. To describe the data we developed a systems-based pharmacokinetic model. Our findings indicated that: (1) brain ECF- and CSF-to-unbound plasma $\mathrm{AUC}_{0-360}$ ratios were all over $100 \%$; (2) P-gp also restricts brain intracellular exposure; (3) a direct transport route of quinidine from plasma to brain cells exists; (4) P-gp-mediated efflux of quinidine at the blood-brain barrier seems to result of combined efflux enhancement and influx hindrance; (5) P-gp at the blood-CSF barrier either functions as an efflux transporter or is not functioning at all. It is concluded that in parallel obtained data on unbound brain $\mathrm{ECF}_{\mathrm{EF}}, \mathrm{CSF}$ and plasma concentrations, under dynamic conditions, is a complex but most valid approach to reveal the mechanisms underlying the
\end{abstract}

Electronic supplementary material The online version of this article (doi:10.1007/s10928-013-9314-4) contains supplementary material, which is available to authorized users.

J. Westerhout · M. Danhof · E. C. M. de Lange $(\square)$

Department of Pharmacology, Leiden/Amsterdam Center

for Drug Research, Einsteinweg 55, 2333 CC Leiden,

The Netherlands

e-mail: 1.lange@lacdr.leidenuniv.nl

J. Smeets

LAP\&P Consultants B.V., Leiden, The Netherlands relationship between brain $_{\mathrm{ECF}}$ and CSF concentrations. This relationship is significantly influenced by activity of P-gp. Therefore, information on functionality of $\mathrm{P}$-gp is required for the prediction of human brain target site concentrations of P-gp substrates on the basis of human CSF concentrations.

Keywords Pharmacokinetics - Blood-brain barrier . P-glycoprotein · Systems-based pharmacokinetic modeling · Brain extracellular fluid · Cerebrospinal fluid

\section{List of symbols}

\section{Variables}

$\mathrm{A}_{\mathrm{i}} \quad$ Amount of quinidine in compartment $\mathrm{i}$ (ng)

$\mathrm{C}_{\mathrm{i}} \quad$ Concentration of quinidine in compartment $\mathrm{i}(\mathrm{ng} / \mathrm{ml})$

$\mathrm{K} \quad$ Rate constant $\left(\mathrm{min}^{-1}\right)$

Q Flow rate $(\mathrm{ml} / \mathrm{min})$

CL Clearance $(\mathrm{ml} / \mathrm{min})$

$\mathrm{V} \quad$ Volume (ml)

\section{Subscripts}

PL Plasma

PL,u Unbound quinidine in plasma

PERi Peripheral compartment $i$

ECF Brain ECF

CSF CSF

LV Lateral ventricle

TFV Third and fourth ventricle

CM Cisterna magna

SAS Subarachnoid space

\section{Introduction}

To be able to predict desired or undesired central nervous system (CNS) drug effects in humans, a mechanistic 
understanding is needed of the individual contributions of the processes involved in brain target site distribution and ultimately drug effects. With the unbound drug concentrations at the brain target site being responsible for the (un)wanted effect it is important to be able to determine or predict unbound drug concentrations at their site of action.

During the preclinical phase of drug development several techniques can be applied to determine or predict brain target site concentrations, which are often closely linked, or equal, to brain extracellular fluid (brain ${ }_{\mathrm{ECF}}$ ) concentrations $[1,2]$. However, most of the preclinical techniques have very limited applicability in the extrapolation of preclinical findings to the human situation [3-5].

Cerebrospinal fluid (CSF) concentrations are often considered to be the best available surrogate for brain target site concentrations in humans [6-10]. It is often assumed that CSF concentrations readily equilibrate with brain ECF concentrations due to the lack of a physical barrier between these sites [11]. However, due to qualitative and quantitative differences in processes that govern the pharmacokinetics (PK) of drugs in the brain, a generally applicable relationship between CSF concentrations and brain ECF concentrations does not exist [5, 12-14].

Transport of drugs into and out of the brain is not solely governed by the blood-brain barriers [the blood-brain barrier (BBB) and the blood-CSF barrier (BCSFB)], but also by the anatomy of the brain and physiological processes. In combination with drug specific properties [15-19], this determines the concentrations of a drug within a specific part of the CNS, including the target site concentrations, which we are ultimately interested in.

We have previously shown that even for acetaminophen, a model compound for passive transport into, within and out of the brain, differences exist between CSF and brai$\mathrm{n}_{\mathrm{ECF}}$ kinetics [20]. For compounds subjected to active transport at the level of the brain barriers, such as by P-gp,

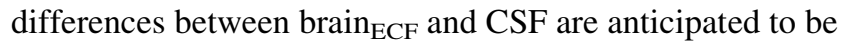
larger. With P-gp localized at both the luminal and abluminal membranes of capillary endothelial cells, as well as to adjacent pericytes and astrocytes [21], this suggests that P-gp may regulate drug transport processes in the entire brain at both the cellular and subcellular level. In contrast, P-gp presence and localization at the BCSFB is still subject of debate, with the only report of presence at the apical surface of the choroid plexus epithelial cells in the rat by Rao and colleagues [22]. Furthermore, it has been well established that P-gp functions as an efflux transporter at the BBB [23-26], whereas, there has been some evidence that P-gp could function as an influx transporter at the BCSFB [22, 27]. This could result in significant differences between concentrations at the brain target site and in CSF for compounds that are substrates for $\mathrm{P}$-gp mediated transport.
The presence of P-gp at multiple sites, with in part a yet uncertain transport direction, could have major implications for the predictability of human brain ${ }_{\mathrm{ECF}}$ concentrations on the basis of human CSF concentrations for compounds that are substrates for P-gp. Consequently, to be able to predict human brain ECF $_{\mathrm{E}}$ concentrations on the basis of human CSF concentrations, one should first understand the mechanisms that determine the relationship between CSF concentrations and brain ECF $_{\text {concentrations. }}$

Previous studies have indicated that, under steady-state conditions, CSF concentrations were comparable to steady-

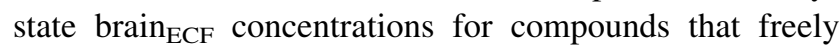
diffuse across the BBB and BCSFB, but may differ for compounds that are substrate for the various active transport systems at the BBB and BCSFB [6-10]. CSF and brain $_{\mathrm{ECF}}$ concentration ratios were considered comparable if smaller than threefold, and assumed to be of little pharmacological consequence.

However, we have previously questioned this arbitrary threefold range in ratio of CSF and brain ${ }_{\mathrm{ECF}}$ (target site) kinetics, especially with regard to the unknown impact of the steady-state situation versus the more realistic multiple dosing conditions (troughs and peaks), the unknown of the changes therein in disease conditions as well as the unknown impact of this range on pharmacodynamics [5]. These unknowns need to be investigated before we can really predict human target site PK and finally CNS effects.

Using the multiple intracerebral probe microdialysis approach [striatum (ST), lateral ventricle (LV), and cisterna magna $(\mathrm{CM})]$ with parallel blood sampling, continuous measurement and direct comparison of changes in concentrations in plasma, brain ${ }_{\mathrm{ECF}}$ and CSF kinetics of quinidine, a well-known P-gp substrate [28-32], could be assessed, following a short infusion of 10 and $20 \mathrm{mg} / \mathrm{kg}$, with and without co-administration of the P-gp blocker tariquidar [33, 34]. Mathematical modelling was applied to the data to result in a number of key findings.

\section{Materials and methods}

\section{Chemicals}

Tariquidar (XR9576, TQD) was obtained from Xenova Group PLC (Cambridge, England) or API Services Inc. (Westford, USA). Quinidine, quinidine sulfate dehydrate, quinidine hemi sulfate and quinine hemi sulfate were obtained from Sigma Aldrich (Zwijndrecht, The Netherlands). Triethyl amine was obtained from J.T. Baker (Deventer, The Netherlands). Boric acid and orthophosphoric acid $85 \%$ were obtained from Merck (Darmstadt, Germany). Methyl tert-butyl ether was obtained from Biosolve B.V. (Valkenswaard, The Netherlands). Isoflurane 
was obtained from Pharmachemie B.V. (Haarlem, The Netherlands). Saline and $5 \%$ glucose were obtained from the Leiden University Medical Centre pharmacy (Leiden, The Netherlands). Microdialysis perfusion fluid was prepared as previously described [20], containing $140.3 \mathrm{mM}$ sodium, $2.7 \mathrm{mM}$ potassium, $1.2 \mathrm{mM}$ calcium, $1.0 \mathrm{mM}$ magnesium and $147.7 \mathrm{mM}$ chloride.

\section{Animals}

The study protocol was approved by the Animal Ethics Committee of Leiden University (UDEC nr. 07142) and all animal procedures were performed in accordance with Dutch laws on animal experimentation. A total of 60 male Wistar WU rats (225-275 g, Charles River, Maastricht, The Netherlands) were randomly divided into two groups; the first group ( $n=12)$ was used for the determination of the in vivo microdialysis probe recovery; the second group $(n=48)$ was used for brain disposition experiments. This second group was further divided into four subgroups, designated for 10 or $20 \mathrm{mg} / \mathrm{kg}$ quinidine with or without co-administration of tariquidar $\left(10^{-}, 10^{+}, 20^{-}\right.$and $\left.20^{+}\right)$.

After arrival, all animals were housed in groups for 5-7 days (Animal Facilities, Gorlaeus Laboratories, Leiden, The Netherlands), under standard environmental conditions (ambient temperature $21{ }^{\circ} \mathrm{C}$; humidity $60 \%$; $12 / 12 \mathrm{~h} \mathrm{light/dark}$ cycle, background noise, daily handling), with ad libitum access to food (Laboratory chow, Hope Farms, Woerden, The Netherlands) and acidified water. Between surgery and experiments, the animals were kept individually in Makrolon type three cages for 7 days to recover from the surgical procedures.

\section{Surgery}

All surgical procedures were performed as described by Westerhout et al. [20]. In short, cannulas were implanted in the left femoral artery and vein for blood sampling and drug administration, respectively. Both cannulas were subcutaneously led to the back of the head and fixated in the neck with a rubber ring. Subsequently, the animals were chronically instrumented with two CMA/12 microdialysis guides (CMA/Microdialysis AB, Stockholm, Sweden) in different combinations of ST, for sampling in brain ECF, and LV and/or CM for sampling in CSF $(\mathrm{ST}+\mathrm{LV}, \mathrm{ST}+\mathrm{CM}$ or $\mathrm{LV}+\mathrm{CM})$. For ST, the position of the microdialysis guide is: $1.0 \mathrm{~mm}$ anterior, $3.0 \mathrm{~mm}$ lateral, $3.4 \mathrm{~mm}$ ventral, relative to bregma. For $\mathrm{LV}$, the position of the microdialysis guide is: $0.9 \mathrm{~mm}$ posterior, $1.6 \mathrm{~mm}$ lateral, $2.9 \mathrm{~mm}$ ventral, relative to the bregma. For $\mathrm{CM}$, the position of the microdialysis guide is: $1.93 \mathrm{~mm}$ posterior, $3.15 \mathrm{~mm}$ lateral, $8.1 \mathrm{~mm}$ ventral, at an angle of $25^{\circ}$ from the dorsoventral axis (towards anterior) and $18^{\circ}$ lateral from the anteroposterior axis relative to lambda. The microdialysis guides were secured to the skull with 3 anchor screws and dental cement.

After the surgery the animals received $0.03 \mathrm{ml}$ Temgesic ${ }^{\circledR}$ intramuscularly (Schering-Plough, Amstelveen, The Netherlands) and $0.3 \mathrm{ml} \mathrm{Ampicillan}{ }^{\circledR}$ (Alfasan B.V., Woerden, The Netherlands) subcutaneously. One day prior to the experiment, the microdialysis dummies were replaced by the microdialysis probes (CMA/12 Elite, Polyarylethersulfone, molecular weight cut-off $20 \mathrm{kDa}, \mathrm{CMA} /$ Microdialysis $\mathrm{AB}$, Stockholm, Sweden, with a semi-permeable membrane length of $4 \mathrm{~mm}$ for ST, and $1 \mathrm{~mm}$ for $\mathrm{LV}$ and $\mathrm{CM}$ ).

\section{Experimental set-up}

All experiments were performed as described by Westerhout et al. [20], with some modifications. In short, the in vivo microdialysis probe recovery of quinidine was determined on the basis of reverse dialysis [35]. The microdialysis probes in ST, LV and $\mathrm{CM}$ were perfused with different concentrations of quinidine $(50,200$ and $1000 \mathrm{ng} / \mathrm{ml}$ ) in perfusion fluid. To evaluate the potential effect of co-administration of tariquidar on the in vivo recovery of quinidine, several animals received an intravenous infusion of $15 \mathrm{mg} / \mathrm{kg}$ in $5 \%$ glucose solution $(100 \mu \mathrm{l} / \mathrm{min} / \mathrm{kg}$ for a period of $10 \mathrm{~min})$ with an automated pump (Pump 22 Multiple Syringe Pump, Harvard Apparatus, Holliston, USA) $30 \mathrm{~min}$ prior to the start of the reverse dialysis experiment. Control animals received an intravenous infusion of vehicle $(100 \mu \mathrm{l} / \mathrm{min} / \mathrm{kg}$ for a period of $10 \mathrm{~min}$ ).

The in vivo recovery is defined as the ratio of the concentration difference between the dialysate $\left(\mathrm{C}_{\text {dial }}\right)$ and perfusion fluid $\left(\mathrm{C}_{\mathrm{in}}\right)$ over the concentration in the perfusion fluid (Eq. 1) [36].

In vivo recovery $=\frac{C_{i n}-C_{\text {dial }}}{C_{\text {in }}}$

For the brain disposition experiments, the rats first received an intravenous infusion of $15 \mathrm{mg} / \mathrm{kg}$ tariquidar in $5 \%$ glucose solution or vehicle $30 \mathrm{~min}$ prior to the administration of 10 or $20 \mathrm{mg} / \mathrm{kg}$ quinidine in saline $(100 \mu \mathrm{l} / \mathrm{min} / \mathrm{kg}$ for a period of $10 \mathrm{~min}$ ). The start and duration of the infusion was corrected for internal volume of the tubing so that infusion started at $\mathrm{t}=0 \mathrm{~min} .10 \mathrm{~min}$ interval samples were collected between $\mathrm{t}=-1 \mathrm{~h}$ to $\mathrm{t}=4 \mathrm{~h}$, followed by $20 \mathrm{~min}$ interval samples from $t=4-6 \mathrm{~h}$. After weighing the microdialysis vials they were stored at $-80{ }^{\circ} \mathrm{C}$ before analysis.

For the determination of quinidine plasma concentrations, blood samples of $100 \mu \mathrm{l}$ were taken, in parallel to the microdialysate samples, from the arterial cannula at $\mathrm{t}=-5$ (blank), 2, 7, 10, 12, 17, 30, 60, 140, 240, and $360 \mathrm{~min}$. All blood samples were temporarily stored in heparin (10 IU) coated 
Eppendorf cups before being centrifuged for $15 \mathrm{~min}$ at 5,000 rpm. The plasma was then pipetted into clean Eppendorf cups and stored at $-20{ }^{\circ} \mathrm{C}$ before analysis.

At the end of the experiments the animals were sacrificed with an overdose of Nembutal (Ceva Sante Animale, Libourne, France). The animals were then perfused and decapitated to isolate the brain. After cleaning with saline, weighing, and freezing in liquid nitrogen, the brain was stored at $-80{ }^{\circ} \mathrm{C}$ before analysis.

\section{Plasma protein binding}

For the determination of plasma protein binding of quinidine, blood samples of $300 \mu$ were taken at $t=-30$ (blank) and 60 min (with a concentration assumed to be approximately $1 / 2 \times \mathrm{C}_{\max }$ [37]). After the blood sample at $\mathrm{t}=360 \mathrm{~min}$, an additional dose of 10 or $20 \mathrm{mg} / \mathrm{kg}$ in 10 min was given to be able to determine plasma protein binding at $\mathrm{C}_{\max }$ (at $\mathrm{t}=370 \mathrm{~min}$ ). All blood samples were temporarily stored in heparin (10 IU) coated Eppendorf cups. The blank blood samples were spiked with quinidine to obtain a blood concentration of $100 \mathrm{ng} / \mathrm{ml}$ for the $10 \mathrm{mg} / \mathrm{kg}$ dose group and $200 \mathrm{ng} / \mathrm{ml}$ for the $20 \mathrm{mg} / \mathrm{kg}$ dose group. The spiked blood samples were then incubated in a shaking water bath at $37{ }^{\circ} \mathrm{C}$ for $30 \mathrm{~min}$. All blood samples were centrifuged for $15 \mathrm{~min}$ at $5,000 \mathrm{rpm}$ and the plasma was pipetted into clean Eppendorf cups and stored at $-20{ }^{\circ} \mathrm{C}$ before analysis.

Plasma protein binding was determined with Centrifree ${ }^{\circledR}$ ultrafiltration devices (Millipore BV, Etten-Leur, the Netherlands). All procedures were performed according to the user's manual. The ultrafiltrate was diluted ten times with saline before the analysis.

\section{Concentration analysis}

Quinidine concentrations in plasma, plasma ultrafiltrate, microdialysate, and total brain were determined as described by Syvänen et al. [32], using high pressure liquid chromatography (HPLC) with fluorescence detection. In short, to $20 \mu \mathrm{l}$ of plasma, $50 \mu \mathrm{l}$ internal standard (IS; $500 \mathrm{ng} / \mathrm{ml}$ quinine) was added. After homogenization with $200 \mu \mathrm{l}$ borate buffer $\mathrm{pH} 10,5 \mathrm{ml}$ of methyl tert-butyl ether was added. After vortexing, centrifugation, and freezing of the aqueous layer, the organic phase was evaporated to dryness. The extracts were reconstituted in $100 \mu \mathrm{l}$ of mobile phase and centrifuged at $4,000 \times g$ during $5 \mathrm{~min}$. The clean plasma extracts were injected using a mobile phase with an acetonitrile/buffer ratio of 1:6.

To $20 \mu \mathrm{l}$ of the plasma ultrafiltrate or microdialysate samples $20 \mu \mathrm{l}$ IS was added, followed by vortexing before being directly injected into the HPLC system. Quinidine concentration in brain tissue was analyzed by the following steps: whole brain was homogenized in $50 \mathrm{mM}$ phosphate buffer at pH 7.4. To $600 \mu \mathrm{l}$ of the homogenate $100 \mu \mathrm{l}$ IS and $100 \mu \mathrm{l} \mathrm{M}$ sodium hydroxide was added. $5 \mathrm{ml}$ methyl tert-butyl ether was then added, followed by vortexing and centrifugation. $4 \mathrm{ml}$ of the supernatant was then transferred to a clean glass tube and $100 \mu \mathrm{l}$ of $30 \mathrm{mM}$ phosphoric acid was added. After vortexing and centrifugation, the supernatants were aspirated and discarded. The remaining aqueous phase was centrifuged for $10 \mathrm{~min}$ at $11,000 \times \mathrm{g}$. An aliquot of $50 \mu \mathrm{l}$ was then transferred to clean glass vials and $20 \mu \mathrm{l}$ was injected into the HPLC system.

Data acquisition and processing was performed using Empower $^{\circledR}$ data acquisition software (Waters, Etten-Leur, The Netherlands). For constructing the calibration curve, linear regression analysis was applied using weight factor $1 /(y)^{2}$. Data analysis, statistical analysis, and plotting were performed using Microsoft ${ }^{\circledR}$ Office Excel 2003 (Microsoft Corporation, USA).

\section{PK data analysis}

All plasma concentrations were converted to unbound plasma concentrations, by correction for plasma protein binding. All microdialysate concentrations from ST, LV and $\mathrm{CM}$ were converted into brain ECF concentrations $\left(\mathrm{C}_{\mathrm{ECF}}\right)$ or $\mathrm{CSF}$ concentrations $\left(\mathrm{C}_{\mathrm{CSF}}\right)$ by division of the dialysate concentrations by the average in vivo recovery as determined for each microdialysis probe location (Eq. 2).

$C_{E C F}$ or $C_{C S F}=\frac{C_{\text {dial }}}{\text { in vivo recovery }}$

Areas under the curve from $\mathrm{t}=0$ to $\mathrm{t}=360 \mathrm{~min}$ $\left(\mathrm{AUC}_{0-360}\right)$ were calculated by the trapezoidal rule and tested for differences by single factor ANOVA. The population PK models were developed and fitted to the data by means of non-linear mixed-effects modeling using the NONMEM software package (version 6.2, Icon Development Solutions, Ellicott City, Maryland, USA) and analyzed using the statistical software package S-Plus ${ }^{\circledR}$ for Windows (version 6.2 Professional, Insightful Corp., Seattle, USA).

The PK model for quinidine plasma and brain concentrations was based on the systems-based PK (SBPK) approach we have previously applied to investigate the exchange between brain ECF and CSF of acetaminophen [20]. For this approach, the volumes of the different brain compartments were fixed to their physiological volumes. The rat brain intracellular space and brain $_{\mathrm{ECF}}$ volume were assumed to be $1.44 \mathrm{ml}$ [38] and $290 \mu \mathrm{l}$ [39], respectively. With a total CSF volume of $300 \mu \mathrm{l}$ in the rat [40], the volumes of the $\mathrm{LV}$, third and fourth ventricles, CM and subarachnoid space were assumed to be $50 \mu \mathrm{l}[41,42]$, $50 \mu \mathrm{l}$ [43], $17 \mu \mathrm{l}$ [44, 45] and $180 \mu \mathrm{l}$ [40, 43], respectively. 
The intra-brain distribution was restricted by the physiological flow paths of brain ECF, in which brain ECF flows towards the CSF compartments at a rate of 0.2 $\mu 1 /$ min $[39,46]$, and CSF flows from LV, through the third and fourth ventricle, to the $\mathrm{CM}$ and subsequently to the subarachnoid space (cranial and spinal) and back into blood at a rate of $2.2 \mu \mathrm{l} / \mathrm{min}$ [47].

Structural model selections for both the blood and brain PK model were based on the likelihood ratio test $(p<0.01)$, diagnostic plots (observed concentrations vs. individual and population predicted concentrations, weighted residuals vs. predicted time and concentrations), parameter correlations and precision in parameter estimates. The inter-animal variability in PK parameters was assumed to be log normally distributed. The residual error, which accounts for unexplained variability (e.g. measurement and experimental error and model-misspecification), was best described with a proportional error model.

The validity of the PK models was investigated by means of a visual predictive check [48-50]. Using the final PK parameter estimates, 1,000 curves were simulated. Subsequently, the median and the 5th and 95th percentile of the predicted concentrations were calculated, which represent the $90 \%$ prediction interval. These were then compared with the observations.

In order to test the ruggedness of the model and estimate the precision of the parameters $n=100$ non-parametric (case resampling) bootstraps were performed. To create the bootstrapped datasets, specific rat data (plasma and microdialysate concentrations) were removed randomly from the datasets and replaced with randomly selected rat data from the complete original dataset. Each of these permutations of the original dataset were fitted with the final model determined based on the original dataset. This results in a series of model fits, each with its own set of parameters. These results were displayed graphically and the descriptive statistics of the parameters were compared to parameter estimates of the final model. Only bootstrap runs that successfully minimized were used in this analysis.

\section{Results}

All results are presented as average values \pm standard error of the mean, unless stated otherwise.

\section{Quinidine PK}

The average unbound plasma (plasma ${ }_{\mathrm{u}}$ ) and unbound brain $\left(\right.$ brain $_{\mathrm{u}}$ ) quinidine concentrations following the 10 and 20 $\mathrm{mg} / \mathrm{kg}$ dose with or without co-administration of tariquidar are shown in Fig. 1. Plasma protein binding of quinidine was linear at an extent of $86.5 \pm 5.5 \%$. It was not affected by co-administration of tariquidar. The co-administration of tariquidar slightly reduced the plasma elimination rate of plasma $_{\mathrm{u}}$ for both 10 and $20 \mathrm{mg} / \mathrm{kg}$ dose of quinidine. Data obtained by microdialysis from the brain ${ }_{\mathrm{ECF}}, \mathrm{LV}\left(\mathrm{CSF}_{\mathrm{LV}}\right)$ and $\mathrm{CM}\left(\mathrm{CSF}_{\mathrm{CM}}\right)$ were corrected for in vivo recovery. The average in vivo recoveries for the brain $_{\mathrm{u}}$ concentrations in ST, LV and $\mathrm{CM}$ probes were not influenced by co-administration of tariquidar and were determined to be $9.1 \pm 0.5,2.9 \pm 0.5$ and $3.5 \pm 0.5 \%$, respectively.

It can be seen that a higher dose of quinidine leads to higher brain $_{\mathrm{u}}$ quinidine concentrations in all brain compartments, but not to the same extent. Tariquidar increased all brain ${ }_{\mathrm{u}}$ quinidine concentrations significantly $(p<0.01)$, but most pronouncedly for brain ${ }_{\mathrm{ECF}}$. The effect of tariquidar
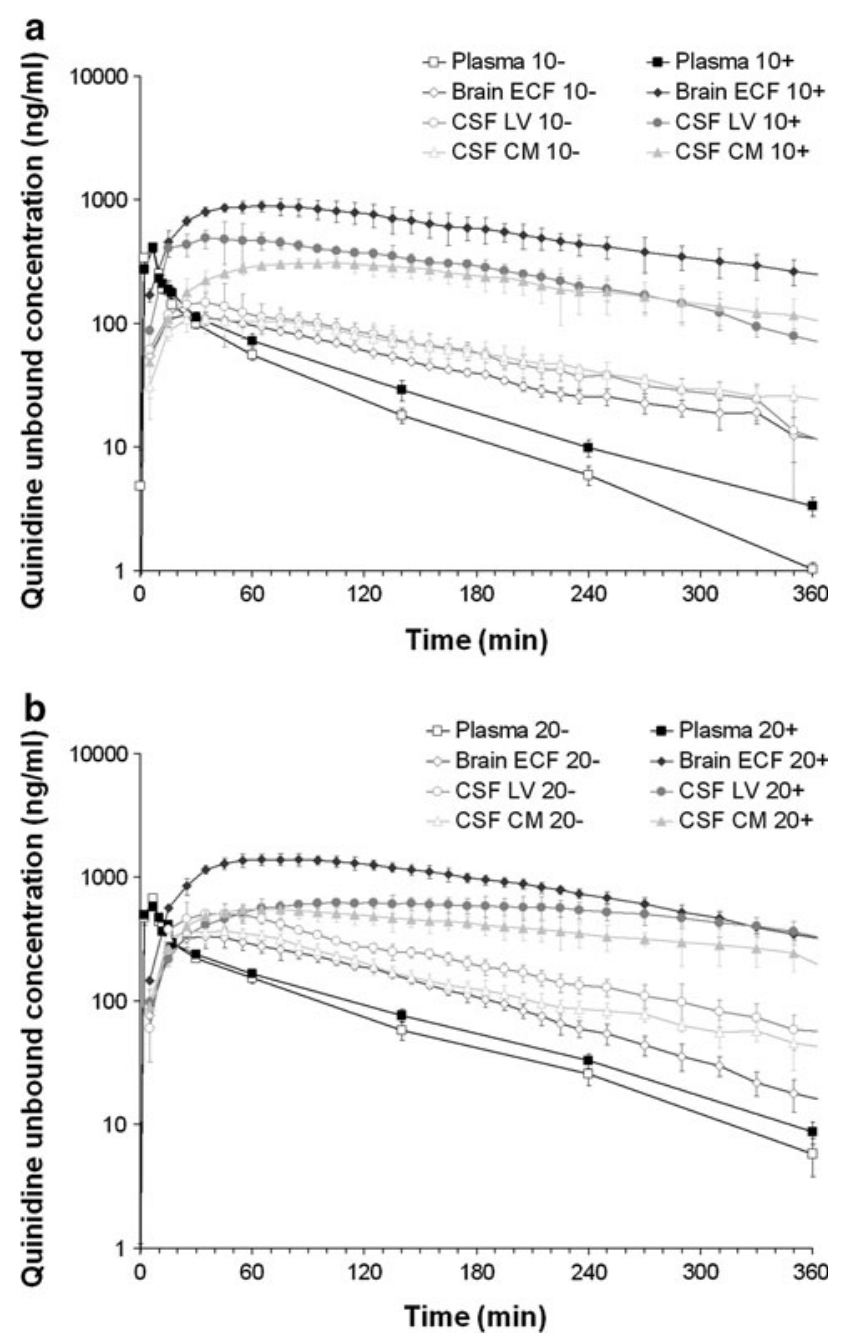

Fig. 1 Average (geometric mean \pm SEM) unbound quinidine concentration-time profiles following intravenous administration of quinidine, with $(+)$ or without $(-)$ co-administration of tariquidar $(15 / \mathrm{mg} / \mathrm{kg})$. a $10 \mathrm{mg} / \mathrm{kg}$ quinidine dose: for plasma $(n=11(-)$ and 6 $(+)), \operatorname{brain}_{\mathrm{ECF}}(n=6(-)$ and $4(+)), \mathrm{CSF}_{\mathrm{LV}}(n=4(-)$ and $3(+))$ and $\operatorname{CSF}_{\mathrm{CM}}(n=4(-)$ and $4(+)$. b $20 \mathrm{mg} / \mathrm{kg}$ quinidine dose. Plasma $(n=9(-)$ and $11(+))$, $\operatorname{brain}_{\mathrm{ECF}}(n=5(-)$ and $6(+)), \mathrm{CSF}_{\mathrm{LV}}$ $(n=4(-)$ and $4(+))$ and $\operatorname{CSF}_{\mathrm{CM}}(n=6(-)$ and $6(+))$ 
was dependent on the quinidine dose; at the higher dose of quinidine, the increase in brain $_{\mathrm{u}}$ quinidine concentrations was less profound, as can be seen by the average brain ${ }_{\mathrm{u}}$-toplasma $_{\mathrm{u}} \mathrm{AUC}_{0-360}$ ratios (Table 1). However, the difference between the brain ${ }_{u}$-to-plasma $A_{u} \mathrm{AUC}_{0-360}$ ratios for the 10 and $20 \mathrm{mg} / \mathrm{kg}$ dose with co-administration of tariquidar

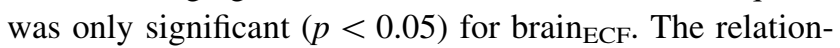
ship between brain ECF$^{-t o-C S F}$ concentrations ratios was also very much dependent on tariquidar, and on average were increased from $0.77 \pm 0.19$ to $2.41 \pm 0.56$ and from $0.67 \pm 0.21$ to $2.02 \pm 0.52$, for the 10 and $20 \mathrm{mg} / \mathrm{kg}$ dose, respectively (Table 2). Significant differences in AUC ratios and concentrations between brain ${ }_{\mathrm{ECF}}$ and CSF (either from $\mathrm{LV}$ or $\mathrm{CM}$ ) were only observed for the groups that received the co-administration of tariquidar.

Also, end-of-experiment total brain concentrations ( brain $_{\text {total }}$ ) were obtained. These data were corrected for corresponding brain $_{\mathrm{ECF}}$ concentrations to represent deep brain (brain deep $_{\text {) }}$ concentrations. The brain $_{\text {deep }}$ concentrations were determined to be on average $3.6 \pm 1.6$-fold higher than final brain $_{\mathrm{ECF}}$ concentrations for the control group and $6.3 \pm 1.5$ fold higher for the animals that received a co-administration of tariquidar (not significantly different). This indicates that P-gp also influences brain intracellular exposure.

\section{Compartmental modeling approach}

All data were subjected first to compartmental PK analysis. It was shown that the plasma concentrations were best described by a three compartment model with inter-compartmental clearance (Q), and elimination clearance from the central compartment $\left(\mathrm{CL}_{\mathrm{E}}\right)$. The effect of the co-administration of tariquidar on the elimination clearance was found to be significant $(p<0.01$, OF value reduction of 6.63 units).

To describe the concentrations in each of the brain compartments, four brain compartments were added (brain $_{\mathrm{ECF}}, \mathrm{CSF}_{\mathrm{LV}}, \mathrm{CSF}_{\mathrm{CM}}$ and brain deep $_{\text {). Drug transport }}$ between the plasma and the different brain compartments was determined by a transfer clearance between plasma and each of the brain compartments $\left(\mathrm{CL}_{\mathrm{PL}-\mathrm{BR}}\right)$ and vice versa $\left(\mathrm{CL}_{\mathrm{BR}-\mathrm{PL}}\right)$. In this model (Fig. 2) it was not possible to include drug transport between the different brain compartments because each brain compartment then has multiple routes of entry. The model was not able to identify the specific contribution of each route, resulting in transfer clearance value estimations near 0 , which is not realistic. Therefore, we decided to remove the transport between the different brain compartments.

\section{Distinction between passive and active transport clearances}

The effect of P-gp on the different transfer clearances between plasma and the brain compartments was determined by comparing the parameter estimations for the rats that did to those rats that did not receive the co-administration of tariquidar. Thus, a distinction could be made between the passive and the active component of the transfer clearances.

The data were best described by a model in which P-gp reduced the transfer clearance from plasma to the brain compartments (i.e. influx hindrance) and increased the transfer clearance from the brain compartments to plasma (i.e. efflux enhancement). The transfer clearances between

Table 1 Brain $_{\mathrm{u}}$-to-plasma $\mathrm{AUC}_{0-360}$ ratios for brain $\mathrm{ECF}, \mathrm{CSF}_{\mathrm{LV}}$ and $\mathrm{CSF}_{\mathrm{CM}}$ for the 10 and $20 \mathrm{mg} / \mathrm{kg}$ dose without (-) and with (+) co-administration of tariquidar

\begin{tabular}{|c|c|c|c|c|}
\hline Brain $_{\mathrm{u}}$-to-plasma ${ }_{\mathrm{u}} \mathrm{AUC}_{0-360}$ ratios & $10^{-}(\%)$ & $10^{+}(\%)$ & $20^{-}(\%)$ & $20^{+}(\%)$ \\
\hline Brain $_{\mathrm{ECF}}$ & $135 \pm 17$ & $1,265 \pm 213^{* * * *}$ & $150 \pm 16^{*}$ & $864 \pm 64 * *$ \\
\hline $\mathrm{CSF}_{\mathrm{LV}}$ & $177 \pm 39$ & $624 \pm 41 * *$ & $257 \pm 24$ & $498 \pm 74 * *$ \\
\hline $\mathrm{CSF}_{\mathrm{CM}}$ & $167 \pm 16$ & $479 \pm 76^{* *}$ & $184 \pm 15$ & $383 \pm 33 * *$ \\
\hline
\end{tabular}

** Significantly $(p<0.01)$ different from the group without co-administration of tariquidar

* Significantly $(p<0.05)$ different from the CSF-to-plasma ${ }_{\mathrm{u}} \mathrm{AUC}_{0-360}$ ratios

$\dagger$ Significantly $(p<0.05)$ different from the $10 \mathrm{mg} / \mathrm{kg}$ dose group with co-administration of tariquidar

Table 2 Brain $_{\mathrm{ECF}}$-to-CSF concentration ratios for the 10 and $20 \mathrm{mg} / \mathrm{kg}$ dose without (-) and with (+) co-administration of tariquidar

\begin{tabular}{lllll}
\hline Brain $_{\mathrm{ECF}}$-to-CSF concentration ratios & $10^{-}$ & $10^{+}$ & $20^{-}$ & $20^{+}$ \\
\hline Brain $_{\mathrm{ECF}}$-to-CSF & & $2.13 \pm 0.47^{*}$ & $0.56 \pm 0.18^{*}$ & $1.81 \pm 0.57$ \\
Brain $_{\mathrm{ECF}}-\mathrm{to}-\mathrm{CSF}_{\mathrm{CM}}$ & $0.75 \pm 0.09^{*}$ & $2.70 \pm 0.51^{*}$ & $0.78 \pm 0.17$ & $2.23 \pm 0.37^{*}$ \\
Brain $_{\mathrm{ECF}}-$ to-CSF & $0.79 \pm 0.25$ & $2.41 \pm 0.56^{*}$ & $0.67 \pm 0.21$ & $2.02 \pm 0.52^{*}$ \\
\hline
\end{tabular}

* Significantly $(p<0.05)$ different from 1 


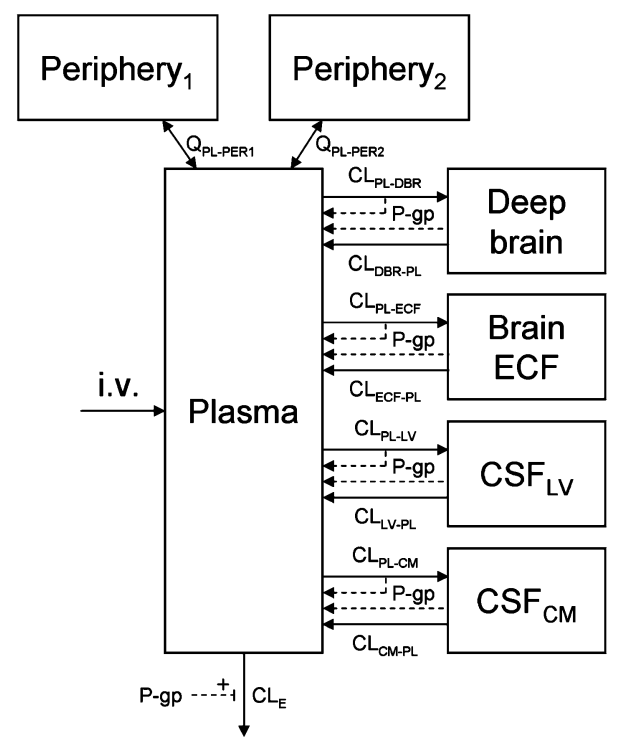

Fig. 2 Diagram of the compartmental model that was used to describe the brain distribution of quinidine in the rat. $\mathrm{CL}_{\mathrm{E}}$ is the elimination clearance from plasma, $\mathrm{Q}_{\mathrm{PL}-\mathrm{PERx}}$ is the inter-compartmental clearance between plasma and the first $(x=1)$ or second $(x=2)$ peripheral compartment. Further, for transfer clearances

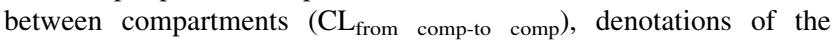
compartments are: $P L$ plasma; $E C F$ brain $_{\mathrm{ECF}} ; D B R$ brain $_{\text {deep }} ; L V$ lateral ventricle; and $C M$ cisterna magna. For peripheral and plasma compartments, $V$ volume of distribution; for brain compartments, $V$ physiological volume, not being shown in the model

plasma and the different brain compartments that could be assigned to P-gp were incorporated into the model as previously described by Syvänen et al. [51]:

$$
\begin{aligned}
& C L_{P L-B R}=C L_{P L-B R, p}-C L_{P L-B R, P-g p} \\
& C L_{B R-P L}=C L_{B R-P L, p}-C L_{B R-P L, P-g p}
\end{aligned}
$$

where the subscript ' $\mathrm{p}$ ' denotes passive transport and 'P-gp' denotes P-gp-mediated transport.

\section{Modeling quinidine concentration-dependent $P$-gp-mediated transport}

Since P-gp-mediated transport is an active (saturable) process we have also tried to identify the maximal transport rate $\left(\mathrm{T}_{\mathrm{m}}\right)$ and the blood- or brain concentration for halfmaximal transport $\left(\mathrm{K}_{\mathrm{m}}\right)$ as follows:

$$
\begin{aligned}
C L_{P L-B R, P-g p} & =\frac{T_{m, P L-B R}}{K_{m, P L-B R}+C_{P L, u}} \\
C L_{B R-P L, P-g p} & =\frac{T_{m, B R-P L}}{K_{m, B R-P L}+C_{B R}}
\end{aligned}
$$

where $\mathrm{C}_{\mathrm{PL}, \mathrm{u}}$ is the unbound plasma concentration and $\mathrm{C}_{\mathrm{BR}}$ is the concentration in one of the brain compartments. The parameter estimations of $T_{m}$ and $K_{m}$ resulted in high values for both $T_{m}$ and $K_{m}$ (results not shown), indicating that the plasma and brain concentrations in this study are not sufficiently high for saturating P-gp-mediated transport. The parameter estimations of $T_{m}$ and $K_{m}$ also resulted in too large coefficients of variation. Thus, our data were insufficient to determine the values of these parameters, and for the next modeling steps, P-gp-mediated transport had to be incorporated by means of a single clearance value, rather than by $\mathrm{T}_{\mathrm{m}}$ and $\mathrm{K}_{\mathrm{m}}$.

\section{Modeling deep brain concentrations}

Brain $_{\text {deep }}$ concentrations were determined for samples obtained at the end-of-experiment time point. Based on previous studies in our lab with male Wistar WU rats (unpublished results), it was found that the brain deep$_{\text {-to-brain }}$ ECF $_{\text {concentration ratio of }}$ quinidine was constant throughout the entire experimental period. We used this information to estimate brain $_{\text {deep }}$ concentrations during the experiment.

\section{Final compartmental model}

The final estimation of the PK parameters of the compartmental model is summarized in Table 3. The visual predictive check of the final compartmental model is given in Fig. 3. It can be seen that the compartmental model describes the data very well within the $95 \%$ prediction interval, and also can cope with the large inter-individual variation as observed in the different brain concentrations. The goodness of fit plots of the plasma, brain $_{\mathrm{ECF}}, \mathrm{CSF}_{\mathrm{LV}}$, $\mathrm{CSF}_{\mathrm{CM}}$ and brain $\mathrm{ECF}_{\mathrm{EC}}$ data with the compartmental model are available as supplemental material.

\section{Systems-based modeling approach}

As it was our goal to investigate the relationship between brain $_{\mathrm{ECF}}$ and CSF PK, we have applied a SBPK modeling approach. To more adequately describe CSF physiology, we have added two CSF compartments that represent the combined third and fourth ventricle $\left(\mathrm{CSF}_{\mathrm{TFV}}\right)$ and the subarachnoid space $\left(\mathrm{CSF}_{\mathrm{SAS}}\right)$, like we did previously for analysis of acetaminophen regional brain distribution [20]. Since we have no measurements of the concentrations in the third and fourth ventricle, the transfer clearance between plasma and third and fourth ventricle was assumed to be equal to the transfer clearance between plasma and LV.

\section{Modeling CSF flow}

In our first attempt of the SBPK approach the values of the brain ECF flow $\left(\mathrm{Q}_{\mathrm{ECF}}\right)$ and $\mathrm{CSF}$ flow $\left(\mathrm{Q}_{\mathrm{CSF}}\right)$ were fixed to their physiological values. However, it appeared that this value for $\mathrm{Q}_{\mathrm{CSF}}$ was too high for proper description of quinidine concentration in the CSF compartments. 
Table 3 Final estimation of the rat PK parameters for the compartmental model ( \pm standard error)

\begin{tabular}{|c|c|}
\hline Parameter & Value \\
\hline $\mathrm{CL}_{\mathrm{E}}$ & $158 \pm 11 \mathrm{ml} / \mathrm{min}$ \\
\hline P-gp effect on $\mathrm{CL}_{\mathrm{E}}$ & $1.2 \pm 0.1$-fold increase \\
\hline $\mathrm{Q}_{\text {PL-PER1 }}$ & $822 \pm 95 \mathrm{ml} / \mathrm{min}$ \\
\hline QPL-PER2 & $171 \pm 28 \mathrm{ml} / \mathrm{min}$ \\
\hline $\mathrm{CL}_{\mathrm{PL}-\mathrm{DBR}, \mathrm{p}}$ & $1,430 \pm 188 \mu 1 / \min$ \\
\hline $\mathrm{CL}_{\mathrm{PL}-\mathrm{DBR}, \mathrm{P}-\mathrm{gp}}$ & $1,270 \pm 165 \mu 1 / \min$ \\
\hline $\mathrm{CL}_{\mathrm{DBR}-\mathrm{PL}, \mathrm{p}}$ & $16.1 \pm 1.3 \mu \mathrm{l} / \mathrm{min}$ \\
\hline $\mathrm{CL}_{\text {DBR-PL,P-gp }}$ & $17.3 \pm 2.4 \mu \mathrm{l} / \mathrm{min}$ \\
\hline $\mathrm{CL}_{\mathrm{PL}-\mathrm{ECF}, \mathrm{p}}$ & $36.6 \pm 3.9 \mu \mathrm{l} / \mathrm{min}$ \\
\hline $\mathrm{CL}_{\mathrm{PL}-\mathrm{ECF}, \mathrm{P}-\mathrm{gp}}$ & $25.8 \pm 3.7 \mu \mathrm{l} / \mathrm{min}$ \\
\hline $\mathrm{CL}_{\mathrm{ECF}-\mathrm{PL}, \mathrm{p}}$ & $3.2 \pm 0.2 \mu 1 / \mathrm{min}$ \\
\hline $\mathrm{CL}_{\mathrm{ECF}-\mathrm{PL}, \mathrm{P}-\mathrm{gp}}$ & $4.4 \pm 0.7 \mu \mathrm{l} / \mathrm{min}$ \\
\hline $\mathrm{CL}_{\mathrm{PL}-\mathrm{LV}, \mathrm{p}}$ & $3.4 \pm 0.7 \mu \mathrm{l} / \mathrm{min}$ \\
\hline $\mathrm{CL}_{\mathrm{PL}-\mathrm{LV}, \mathrm{P}-\mathrm{gp}}$ & $1.1 \pm 0.3 \mu 1 / \mathrm{min}$ \\
\hline $\mathrm{CL}_{\mathrm{LV}-\mathrm{PL}, \mathrm{p}}$ & $0.4 \pm 0.09 \mu \mathrm{l} / \mathrm{min}$ \\
\hline $\mathrm{CL}_{\mathrm{LV}-\mathrm{PL}, \mathrm{P}-\mathrm{gp}}$ & $0.5 \pm 0.2 \mu \mathrm{l} / \mathrm{min}$ \\
\hline $\mathrm{CL}_{\mathrm{PL}-\mathrm{CM}, \mathrm{p}}$ & $0.7 \pm 0.08 \mu 1 / \mathrm{min}$ \\
\hline $\mathrm{CL}_{\mathrm{PL}-\mathrm{CM}, \mathrm{P}-\mathrm{gp}}$ & $0.07 \pm 0.02 \mu \mathrm{l} / \mathrm{min}$ \\
\hline $\mathrm{CL}_{\mathrm{CM}-\mathrm{PL}, \mathrm{p}}$ & $0.1 \pm 0.02 \mu 1 / \mathrm{min}$ \\
\hline $\mathrm{CL}_{\mathrm{CM}-\mathrm{PL}, \mathrm{P}-\mathrm{gp}}$ & $0.2 \pm 0.06 \mu 1 / \mathrm{min}$ \\
\hline $\mathrm{V}_{\mathrm{PL}}$ & $10.6 \mathrm{ml}[52]$ \\
\hline $\mathrm{V}_{\text {PER1 }}$ & $5.9 \pm 0.51$ \\
\hline $\mathrm{V}_{\text {PER2 }}$ & $11.7 \pm 1.61$ \\
\hline $\mathrm{V}_{\mathrm{DBR}}$ & $1.44 \mathrm{ml}[38]$ \\
\hline $\mathrm{V}_{\mathrm{ECF}}$ & $290 \mu l[39]$ \\
\hline $\mathrm{V}_{\mathrm{LV}}$ & $50 \mu l[41,42]$ \\
\hline $\mathrm{V}_{\mathrm{CM}}$ & $17 \mu l[44,45]$ \\
\hline$\eta_{\text {CLE }}$ & $0.08 \pm 0.02$ \\
\hline$\varepsilon_{\mathrm{PL}}$ & $0.13 \pm 0.02$ \\
\hline$\varepsilon_{\mathrm{DBR}}$ & $0.06 \pm 0.01$ \\
\hline$\varepsilon_{\mathrm{ECF}}$ & $0.05 \pm 0.01$ \\
\hline$\varepsilon_{\mathrm{LV}}$ & $0.09 \pm 0.02$ \\
\hline$\varepsilon_{\mathrm{CM}}$ & $0.07 \pm 0.01$ \\
\hline
\end{tabular}

Parameter values in italic are derived from literature. $\mathrm{CL}_{\mathrm{E}}$ is the elimination clearance from plasma, $\mathrm{Q}_{\mathrm{PL}-\mathrm{PERx}}$ is the inter-compartmental clearance between plasma and the first $(x=1)$ or second $(\mathrm{x}=2)$ peripheral compartment. Further, for transfer clearances between compartments $\left(\mathrm{CL}_{\text {from comp-to comp }}\right)$, denotations of the compartments are: $P L$ plasma; $E C F$ brain $_{\mathrm{ECF}} ; D B R$ brain $_{\text {deep }} ; L V$ lateral ventricle; and $C M$ cistern magna. For peripheral and plasma compartments, $V$ volume of distribution; for brain compartments, $V$ volume. $\eta_{i}$ inter-individual variability of parameter $\mathrm{i} ; \varepsilon_{j}$ residual error on concentrations in compartment $\mathrm{j}$. The additional subscripts 'p' and 'P-gp' denote passive transport and P-gp-mediated transport, respectively

Therefore the CSF production rate was estimated. To do so, the clearance from $\mathrm{CSF}_{\mathrm{LV}}$ to plasma was fixed to 0 , as otherwise $\mathrm{Q}_{\mathrm{CSF}}$ was estimated to be 0 . Thereby, the model was 'forced' to estimate the $\mathrm{Q}_{\mathrm{CSF}}$, being $0.52 \pm 0.25$ $\mu 1 /$ min. This value of $\mathrm{Q}_{\mathrm{CSF}}$ was much lower than the physiological one $(2.2 \mu \mathrm{l} / \mathrm{min})$. An explanation for the reduced $\mathrm{Q}_{\mathrm{CSF}}$ was searched for. It was found that quinidine is capable of inhibiting $\mathrm{Na}^{+}-\mathrm{K}^{+}$-ATPase activity [53], which is an enzyme at the apical membrane of the choroid plexus that leads to the formation of CSF [54, 55]. A potential influence of quinidine reducing CSF flow was investigated by a CSF quinidine concentration $\left(\mathrm{C}_{\mathrm{CSF}}\right)$ dependent inhibition of $\mathrm{Q}_{\mathrm{CSF}}$ by means of an $\mathrm{E}_{\max }$ model (Eq. 7), in which $\mathrm{Q}_{\mathrm{CSF} \text { EF }}$ was the effective CSF flow.

$Q_{C S F, E F}=Q_{C S F}\left(1-\frac{C_{C S F}}{C_{C S F}+I C_{50}}\right)$

The resulting estimated $\mathrm{IC}_{50}$ of quinidine was $209 \pm 66 \mathrm{ng} / \mathrm{ml}$. This value was 143 -fold lower than reported ( $\sim 30 \mu \mathrm{g} / \mathrm{ml}$, [53]) and not considered realistic. As an alternative, we needed to fix the $\mathrm{Q}_{\mathrm{CSF}}$ to its physiological value and to define the rate of transfer of quinidine from blood to $\mathrm{CSF}_{\mathrm{LV}}$ and vice versa being equal.

\section{Modeling P-gp-mediated transport}

P-gp has been well described as an efflux transporter at the BBB [23-26]. However, the mechanism by which P-gp can exert its effect could be by so-called efflux enhancement or influx hindrance or both. The data were best described by the model with P-gp function solely as influx hindrance or combined influx hindrance and efflux enhancement. The observation that in vivo probe recovery of quinidine was not affected by tariquidar would be an indication that quinidine is transported by P-gp only via the influx hindrance mechanism [28, 56, 57]. However, as the largest reduction in the objective function value in the model was observed for a combined influx hindrance and efflux enhancement, this indicates that this model is most probably the best.

Based on the suggestion that P-gp functions as an influx transporter at the BCSFB [22, 27], the effect of P-gp on the clearance values between plasma and CSF was described as such. However, with our data we could not identify P-gp influx at the BCSFB. Therefore, we have tested models in which P-gp was considered to be an efflux transporter at the BCSFB or not present at the BCSFB at all. The data were best described by a model with P-gp as an efflux transporter at the BCSFB for LV, whereas it was absent for CM.

Again, we have tried to identify $T_{m}$ and $K_{m}$ values for P-gp-mediated transport of the SBPK model, but without success (results not shown). Therefore, P-gp-mediated transport had to be incorporated by means of a single clearance value, rather than by $\mathrm{T}_{\mathrm{m}}$ and $\mathrm{K}_{\mathrm{m}}$. 
Fig. 3 The visual predictive check of the compartmental model. The dots represent the individual data points and the gray area represents the $95 \%$ prediction confidence interval. The different boxes represent the plasma, brain ${ }_{\mathrm{ECF}}, \mathrm{CSF}_{\mathrm{LV}}$, $\mathrm{CSF}_{\mathrm{CM}}$ and brain deep $_{\text {data }}$

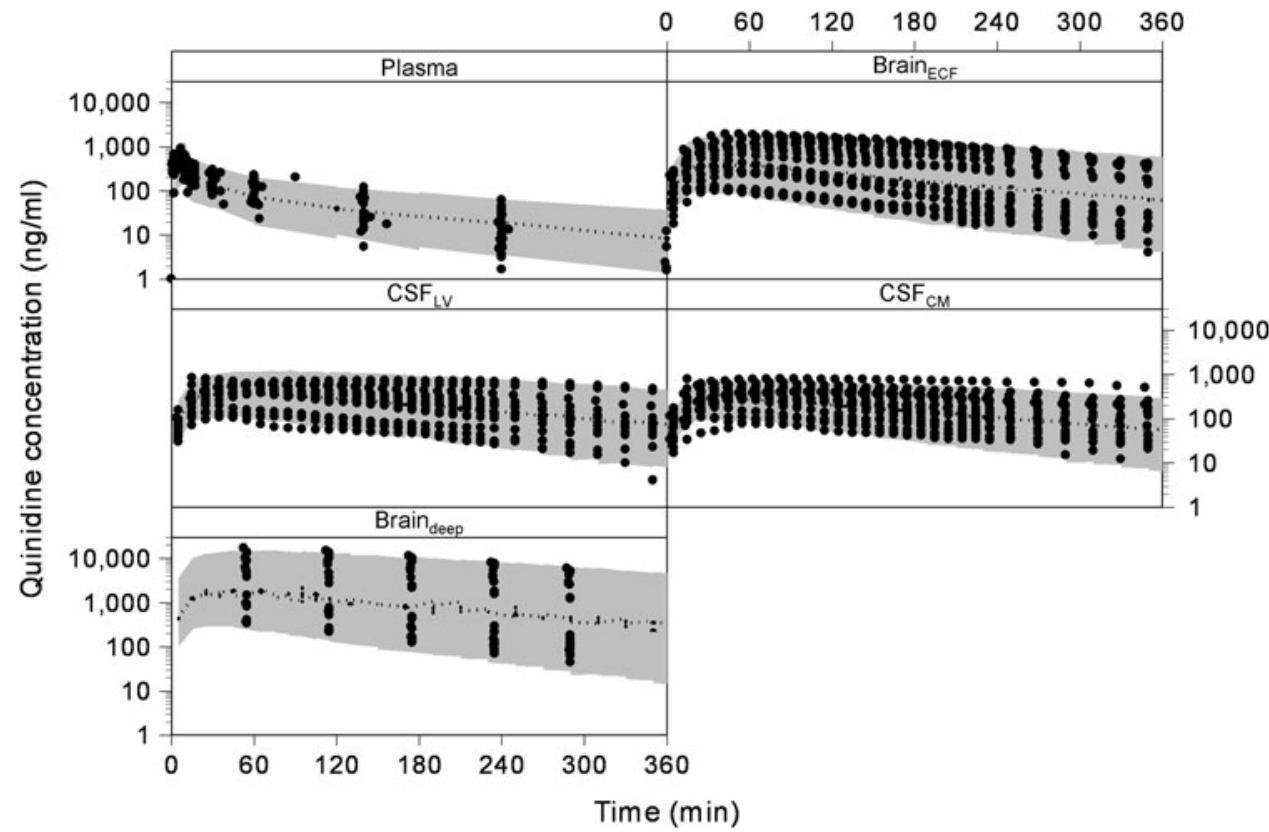

\section{Modeling deep brain concentrations}

Our assumption was that compounds, after passing the BBB and $\mathrm{BCSFB}$ would first enter brain $_{\mathrm{ECF}}$, before reaching the brain $_{\text {deep }}$ compartment. However, since the brain ${ }_{\text {deep }}$ concentrations are much higher than the brain ${ }_{\mathrm{ECF}}$ concentrations, and the physiological volume of the brain $n_{\text {deep }}$ compartment is much larger than the brain $_{\mathrm{ECF}}$ compartment, the mass transfer of quinidine from plasma, via the brain $_{\mathrm{ECF}}$ compartment, to the deep brain needs to be quite substantial. This route did not result in a model that could adequately describe the data. In contrast, a direct mass transfer from plasma into the brain $_{\text {deep }}$ compartment did. Actually, the direct route through lipid membranes seems a rather plausible explanation for a lipophilic drug like quinidine, which has a $\log \mathrm{P}$ of 2.36 in its neutral form [58].

\section{Final SBPK model}

The final SBPK model is shown in Fig. 4. The differential equations of this model can be found in the appendix. The final estimation of the PK parameters is summarized in Table 4. Here, the parameters are the same as for Table 3, with the addition of the following: $\mathrm{CL}_{\mathrm{PL}-\mathrm{TFV}}$ is the clearance from plasma to $\mathrm{CSF}_{\mathrm{TFV}}, \mathrm{CL}_{\mathrm{TFV}-\mathrm{PL}}$ is the clearance from $\mathrm{CSF}_{\mathrm{TFV}}$ to plasma, $\mathrm{Q}_{\mathrm{ECF}}$ is the flow rate of brain $\mathrm{ECF}$, $\mathrm{Q}_{\mathrm{CSF}}$ is the flow rate of CSF, $\mathrm{V}_{\mathrm{TFV}}$ is the volume of the third and fourth ventricle combined and $\mathrm{V}_{\mathrm{SAS}}$ is the volume of the subarachnoid space.

The visual predictive check of the final model is given in Fig. 5. It can be seen that the final model describes the data very well within the $95 \%$ prediction interval, and also can cope with the large inter-individual variation in brain concentrations. The goodness of fit plots of the plasma, brain $_{\mathrm{ECF}}, \mathrm{CSF}_{\mathrm{LV}}, \mathrm{CSF}_{\mathrm{CM}}$ and brain $\mathrm{ECF}_{\mathrm{EC}}$ data with the final SBPK model are available as supplemental material.

\section{Discussion}

In the development of CNS-targeted drugs, the prediction of human CNS target exposure is a big challenge. While CSF concentrations are often considered to be the best available surrogate for brain target site concentrations in humans, a generally applicable relationship between CSF concentrations and brain $_{\mathrm{ECF}}$ concentrations does not exist. [5, 12-14] Previous studies have indicated that, at steadystate conditions, CSF to brain ${ }_{\mathrm{ECF}}$ concentration ratios were between threefold (either higher or lower) for compounds that freely diffuse across the BBB and BCSFB, while for compounds being brain barrier transporter substrates the difference may be higher [6-10]. Combining their data showed that $24 \%(21 / 89)$ of the P-gp substrates had a CSF-to-brain $_{\mathrm{ECF}}$ concentration ratio larger than 3. Then, prediction of brain $_{\mathrm{ECF}}$ concentrations on the basis of CSF concentrations gets inadequate. This indicates that we need to improve our understanding of the impact of P-gp functionality at the brain barriers in order to be able to predict human CNS brain ECF $_{\text {concentrations. }}$

By using the multiple microdialysis probe approach [20], we investigated the direct relationships between brain ST concentrations and those in different CSF locations, and unbound plasma concentrations in the rat. We have focused on P-gp-mediated efflux transport functionality whereas it has been reported to function as an influx transporter at the BCSFB [22, 27]. This could have major implications for 


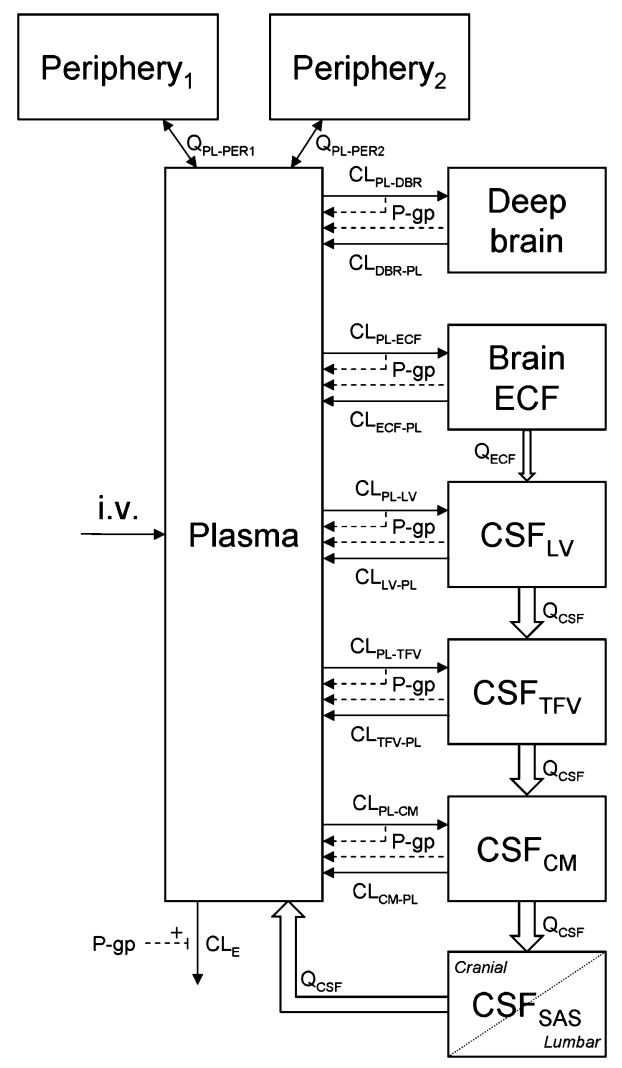

Fig. 4 Diagram of the SBPK model that was used to describe the intra-brain distribution in the rat. $\mathrm{CL}_{\mathrm{E}}$ is the elimination clearance from plasma, $\mathrm{Q}_{\mathrm{PL}-\mathrm{PERx}}$ is the inter-compartmental clearance between plasma and the first $(\mathrm{x}=1)$ or second $(\mathrm{x}=2)$ peripheral compartment. Further, for transfer clearances between compartments $\left(\mathrm{CL}_{\text {from }}\right.$ comp-to comp), denotations of the compartments are: $P L$ plasma; $E C F$ brain $_{\mathrm{ECF}} ; D B R$ brain $_{\text {deep }} ; L V$ lateral ventricle; $T F V$ third and fourth ventricle; $C M$ cisterna magna and $S A S$ subarachnoid space. $\mathrm{Q}_{\mathrm{ECF}}$ is the flow rate of brain ECF, $Q_{\mathrm{CSF}}$ is the flow rate of CSF. For peripheral and plasma compartments, $V$ volume of distribution; for brain compartments, $V$ volume, not shown in the diagram

the relationship between CSF concentrations and brain ECF concentrations for compounds that are substrates for P-gp-mediated transport. To investigate the specific contribution of P-gp-mediated transport, quinidine was used as a paradigm P-gp substrate, with inhibition of P-gp by co-administration of tariquidar. Tariquidar is known to inhibit P-gp with a half-maximum inhibition constant $\left(\mathrm{IC}_{50}\right)$ of approximately $25 \mathrm{ng} / \mathrm{ml}$ [59]. Previous work by Bankstahl et al. [60] and Syvänen et al. [61] have indicated that a $15 \mathrm{mg} / \mathrm{kg}$ dose of tariquidar results in plasma and brain concentrations over 50 -fold higher than the $\mathrm{IC}_{50}$ value up to $3 \mathrm{~h}$ after administration. Therefore, it is plausible to assume that the dose of tariquidar is sufficient to fully inhibit P-gp throughout the entire experimental period. Advanced mathematical modelling was used to finally determine the interaction between systems physiology and quinidine. Our key findings indicated that: (1) brain $_{\mathrm{ECF}^{-}}$ and CSF-to-unbound plasma $\mathrm{AUC}_{0-360}$ ratios were all over
$100 \%$, indicating influx transport by using unbound concentrations; (2) P-gp also restricts brain intracellular exposure; (3) a direct transport route of quinidine from plasma to brain cells exists; (4) P-gp-mediated efflux of quinidine at the BBB seems to result of combined efflux enhancement and influx hindrance; (5) P-gp at the BCSFB at the level of the LV functions as an efflux transporter or, at the CM, is not functioning at all.

In previous studies brain ${ }_{\mathrm{ECF}}$ concentrations were estimated on the basis of total brain concentrations and the brain unbound fraction, determined by equilibrium dialysis of drug-spiked brain homogenates [6-8]. However, brain tissue homogenization destroys cell structures unmasking binding sites that are normally not accessible to a drug [9], potentially leading to underestimation of the in vivo brain unbound fraction. The use of the brain slice technique is an improvement [62]. Liu et al. [8], and Fridén et al. [10], have applied this technique to calculate the brain unbound fraction, being further used to estimate brain $_{\mathrm{ECF}}$ concentrations. Comparison of the brain homogenate method with brain slice technique indicated that the brain unbound fraction was over $50 \%$ different for 5 out of 7 compounds [8]. Liu and colleagues [9] have later applied the microdialysis technique for direct measurement of unbound brain $_{\mathrm{ECF}}$ concentrations and compared those to CSF concentrations sampled at steady-state. They found that the

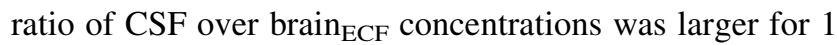
out of the 7 P-gp substrates.

To our surprise, we found that unbound concentrations in brain were significantly larger than unbound concentrations in plasma. This appears to be in contrast to previous studies by Liu et al. [9] and Kodaira et al. [63] in which unbound brain-to-unbound plasma $\left(\right.$ brain $_{\mathrm{u}} /$ plasma $\left._{\mathrm{u}}\right)$ concentration ratios at assumed steady state were well below unity. While our results were quite comparable to the results of Liu et al. [9] and Kodaira et al. [63], a substantial difference was found for the (calculated) unbound brain (ECF) concentrations between these studies, and ours. Liu et al. determined the brain free fraction with the brain homogenate method and found an unbound brain fraction comparable to the unbound brain fraction that was found by Kodaira et al. by the brain slice technique (3.6 and $2.4 \%$, respectively). In contrast, the unbound brain fraction in our study was calculated to be $28 \%$ (brain $_{\mathrm{ECF}}$ concentration divided by the total brain concentration). However, Liu et al. reported a 3-fold difference in the brain $_{\mathrm{u}}$ concentrations when calculated on the basis of the brain homogenate free fraction, compared to using microdialysis data when corrected for in vitro recovery [9]. We measured both in vitro (33\%) and in vivo recovery ( $9 \%)$, and found that the in vivo recovery was 3.5 -fold lower. If we would calculate the brain $_{\mathrm{ECF}} /$ plasma $_{\mathrm{u}}$ concentration ratio at maximal concentrations, like Liu et al. did, and 
Table 4 Final estimation of the rat PK parameters for the different SBPK models ( \pm standard error)

\begin{tabular}{|c|c|c|c|}
\hline Parameter & Efflux enhancement & Influx hindrance & Efflux enhancement and influx hindrance \\
\hline Objective function value & 18,105 & 18,030 & 17,969 \\
\hline $\mathrm{CL}_{\mathrm{E}}$ & $81.6 \pm 11.4 \mathrm{ml} / \mathrm{min}$ & $87.4 \pm 10.5 \mathrm{ml} / \mathrm{min}$ & $95.9 \pm 11.0 \mathrm{ml} / \mathrm{min}$ \\
\hline P-gp effect on $\mathrm{CL}_{\mathrm{E}}$ & $1.9 \pm 0.2$-fold increase & $2.1 \pm 0.3$-fold increase & $1.9 \pm 0.2$-fold increase \\
\hline$Q_{\text {PL-PER } 1}$ & $1,520 \pm 177 \mathrm{ml} / \mathrm{min}$ & $1,150 \pm 138 \mathrm{ml} / \mathrm{min}$ & $1,190 \pm 135 \mathrm{ml} / \mathrm{min}$ \\
\hline Q $_{\text {PL-PER2 }}$ & $84.2 \pm 57.6 \mathrm{ml} / \mathrm{min}$ & $360 \pm 105 \mathrm{ml} / \mathrm{min}$ & $333 \pm 94 \mathrm{ml} / \mathrm{min}$ \\
\hline $\mathrm{CL}_{\mathrm{PL}-\mathrm{DBR}, \mathrm{p}}$ & $1,540 \pm 182 \mu 1 / \min$ & $2,670 \pm 501 \mu 1 / \min$ & $2,180 \pm 384 \mu 1 / \min$ \\
\hline $\mathrm{CL}_{\mathrm{PL}-\mathrm{DBR}, \mathrm{P}-\mathrm{gp}}$ & NA & $2,430 \pm 466 \mu 1 / \min$ & $1,900 \pm 373 \mu 1 / \min$ \\
\hline $\mathrm{CL}_{\mathrm{DBR}-\mathrm{PL}, \mathrm{p}}$ & $17.8 \pm 1.5 \mu 1 / \mathrm{min}$ & $48.5 \pm 9.6 \mu 1 / \mathrm{min}$ & $37.2 \pm 7.2 \mu 1 / \mathrm{min}$ \\
\hline $\mathrm{CL}_{\text {DBR-PL,P-gp }}$ & $253 \pm 40.4 \mu 1 / \min$ & NA & $19.6 \pm 10.9 \mu 1 / \min$ \\
\hline $\mathrm{CL}_{\mathrm{PL}-\mathrm{ECF}, \mathrm{p}}$ & $48.6 \pm 6.3 \mu 1 / \mathrm{min}$ & $68.4 \pm 9.1 \mu 1 / \mathrm{min}$ & $50.2 \pm 5.0 \mu 1 / \mathrm{min}$ \\
\hline $\mathrm{CL}_{\mathrm{PL}-\mathrm{ECF}, \mathrm{P}-\mathrm{gp}}$ & NA & $54.8 \pm 8.1 \mu \mathrm{l} / \mathrm{min}$ & $33.8 \pm 5.1 \mu 1 / \mathrm{min}$ \\
\hline $\mathrm{CL}_{\mathrm{ECF}-\mathrm{PL}, \mathrm{p}}$ & $7.1 \pm 1.2 \mu 1 / \mathrm{min}$ & $9.3 \pm 1.4 \mu \mathrm{l} / \mathrm{min}$ & $6.3 \pm 0.8 \mu \mathrm{l} / \mathrm{min}$ \\
\hline $\mathrm{CL}_{\mathrm{ECF}-\mathrm{PL}, \mathrm{P}-\mathrm{gp}}$ & $33.1 \pm 8.1 \mu \mathrm{l} / \mathrm{min}$ & NA & $5.3 \pm 1.7 \mu \mathrm{l} / \mathrm{min}$ \\
\hline $\mathrm{CL}_{\mathrm{PL}-\mathrm{LV}, \mathrm{p}}$ & $7.2 \pm 0.8 \mu \mathrm{l} / \mathrm{min}$ & $8.4 \pm 0.8 \mu \mathrm{l} / \mathrm{min}$ & $9.0 \pm 0.9 \mu \mathrm{l} / \mathrm{min}$ \\
\hline CL $L_{\text {PL-LV,P-gp }}$ & NA & $3.0 \pm 0.7 \mu \mathrm{l} / \mathrm{min}$ & $3.8 \pm 0.8 \mu \mathrm{l} / \mathrm{min}$ \\
\hline $\mathrm{CL}_{\mathrm{LV}-\mathrm{PL}, \mathrm{p}}$ & $0.03 \pm 0.01 \mu \mathrm{l} / \mathrm{min}$ & $0.04 \pm 0.01 \mu \mathrm{l} / \mathrm{min}$ & $0.04 \pm 0.01 \mu \mathrm{l} / \mathrm{min}$ \\
\hline $\mathrm{CL}_{\mathrm{LV}-\mathrm{PL}, \mathrm{P}-\mathrm{gp}}$ & $1.2 \pm 0.4 \mu \mathrm{l} / \mathrm{min}$ & NA & $0 \mu 1 / \min$ \\
\hline $\mathrm{CL}_{\mathrm{PL}-\mathrm{CM}, \mathrm{p}}$ & $1.3 \pm 0.3 \mu \mathrm{l} / \mathrm{min}$ & $1.1 \pm 0.3 \mu \mathrm{l} / \mathrm{min}$ & $1.1 \pm 0.3 \mu \mathrm{l} / \mathrm{min}$ \\
\hline $\mathrm{CL}_{\mathrm{PL}-\mathrm{CM}, \mathrm{P}-\mathrm{gp}}$ & NA & $0 \mu \mathrm{l} / \mathrm{min}$ & $0 \mu \mathrm{l} / \mathrm{min}$ \\
\hline $\mathrm{CL}_{\mathrm{CM}-\mathrm{PL}, \mathrm{p}}$ & $3.7 \pm 0.5 \mu \mathrm{l} / \mathrm{min}$ & $4.0 \pm 0.5 \mu \mathrm{l} / \mathrm{min}$ & $4.1 \pm 0.5 \mu \mathrm{l} / \mathrm{min}$ \\
\hline $\mathrm{CL}_{\mathrm{CM}-\mathrm{PL}, \mathrm{P}-\mathrm{gp}}$ & $0 \mu \mathrm{l} / \mathrm{min}$ & NA & $0 \mu 1 / \min$ \\
\hline $\mathrm{Q}_{\mathrm{ECF}}$ & $0.2 \mu \mathrm{l} / \mathrm{min}[39,46]$ & $0.2 \mu \mathrm{l} / \mathrm{min}[39,46]$ & $0.2 \mu \mathrm{l} / \min [39,46]$ \\
\hline $\mathrm{Q}_{\mathrm{CSF}}$ & $2.2 \mu \mathrm{l} / \mathrm{min}[47]$ & $2.2 \mu \mathrm{l} / \mathrm{min}[47]$ & $2.2 \mu \mathrm{l} / \mathrm{min}[47]$ \\
\hline $\mathrm{V}_{\mathrm{PL}}$ & $10.6 \mathrm{ml}[52]$ & $10.6 \mathrm{ml}[52]$ & $10.6 \mathrm{ml}[52]$ \\
\hline $\mathrm{V}_{\text {PER1 }}$ & $13.2 \pm 1.81$ & $6.4 \pm 1.61$ & $6.8 \pm 1.71$ \\
\hline $\mathrm{V}_{\text {PER2 }}$ & $5.8 \pm 2.61$ & $13.9 \pm 2.01$ & $13.3 \pm 2.21$ \\
\hline $\mathrm{V}_{\mathrm{DBR}}$ & $1.44 \mathrm{ml}[38]$ & $1.44 \mathrm{ml}[38]$ & $1.44 \mathrm{ml}[38]$ \\
\hline $\mathrm{V}_{\mathrm{ECF}}$ & $290 \mu l[39]$ & $290 \mu l[39]$ & $290 \mu l[39]$ \\
\hline $\mathrm{V}_{\mathrm{LV}}$ & $50 \mu l[41,42]$ & $50 \mu l[41,42]$ & $50 \mu l[41,42]$ \\
\hline $\mathrm{V}_{\mathrm{TFV}}$ & $50 \mu 1[43]$ & $50 \mu 1[43]$ & $50 \mu 1[43]$ \\
\hline $\mathrm{V}_{\mathrm{CM}}$ & $17 \mu l[44,45]$ & $17 \mu l[44,45]$ & $17 \mu l[44,45]$ \\
\hline $\mathrm{V}_{\text {SAS }}$ & $180 \mu l[40,43]$ & $180 \mu l[40,43]$ & $180 \mu l[40,43]$ \\
\hline$\eta_{\mathrm{CL} 10}$ & $0.20 \pm 0.09$ & $0.16 \pm 0.08$ & $0.14 \pm 0.06$ \\
\hline$\varepsilon_{\mathrm{PL}}$ & $0.29 \pm 0.04$ & $0.22 \pm 0.02$ & $0.22 \pm 0.03$ \\
\hline$\varepsilon_{\mathrm{DBR}}$ & $0.06 \pm 0.01$ & $0.07 \pm 0.02$ & $0.07 \pm 0.02$ \\
\hline$\varepsilon_{\mathrm{ECF}}$ & $0.07 \pm 0.01$ & $0.07 \pm 0.01$ & $0.06 \pm 0.01$ \\
\hline$\varepsilon_{\mathrm{LV}}$ & $0.10 \pm 0.01$ & $0.10 \pm 0.01$ & $0.11 \pm 0.02$ \\
\hline$\varepsilon_{\mathrm{CM}}$ & $0.06 \pm 0.01$ & $0.07 \pm 0.01$ & $0.08 \pm 0.02$ \\
\hline
\end{tabular}

Parameter values in italic are derived from literature; NA implicates that the parameter is not available in the specific model

assume that for Liu also a 3.5-fold lower in vivo recovery would apply, then the brain ${ }_{\mathrm{ECF}} /$ plasma $_{\mathrm{u}}$ concentration ratio would be comparable to ours.

For the brain $\mathrm{ECF} /$ plasma $_{\mathrm{u}} \mathrm{AUC}_{0-360}$ ratios, we found values significantly larger than unity as in the elimination phase the rate of decline in plasma concentrations was

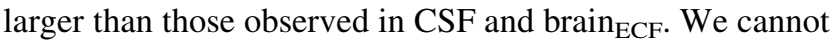
compare these findings with Kodaira and Liu because their studies did not include an elimination phase.
Therefore, based on our data, it appears that quinidine is also transported by other transporters at the BBB and $\mathrm{BCSFB}$, in the direction of the brain. However, there is no direct information in literature to support this. We could only find the following potential contributions: Van Montfoort et al. [64] reported that quinidine is transported by OCTs. This observation was made in an in vitro study, and was found to occur for a $\mathrm{pH}$ of 6 , but not significantly at $\mathrm{pH}$ 7.4. The question remains how this relates to the 
Fig. 5 The visual predictive check of the final SBPK model. The dots represent the individual data points and the gray area represents the $95 \%$ prediction confidence interval. The $x$ axis represents the time $(\min )$ and the $y$ axis represents the quinidine concentrations (ng/ml). The different boxes represent the plasma, brain $\mathrm{ECF}, \mathrm{CSF}_{\mathrm{LV}}, \mathrm{CSF}_{\mathrm{CM}}$ and brain $_{\text {deep }}$ data, respectively

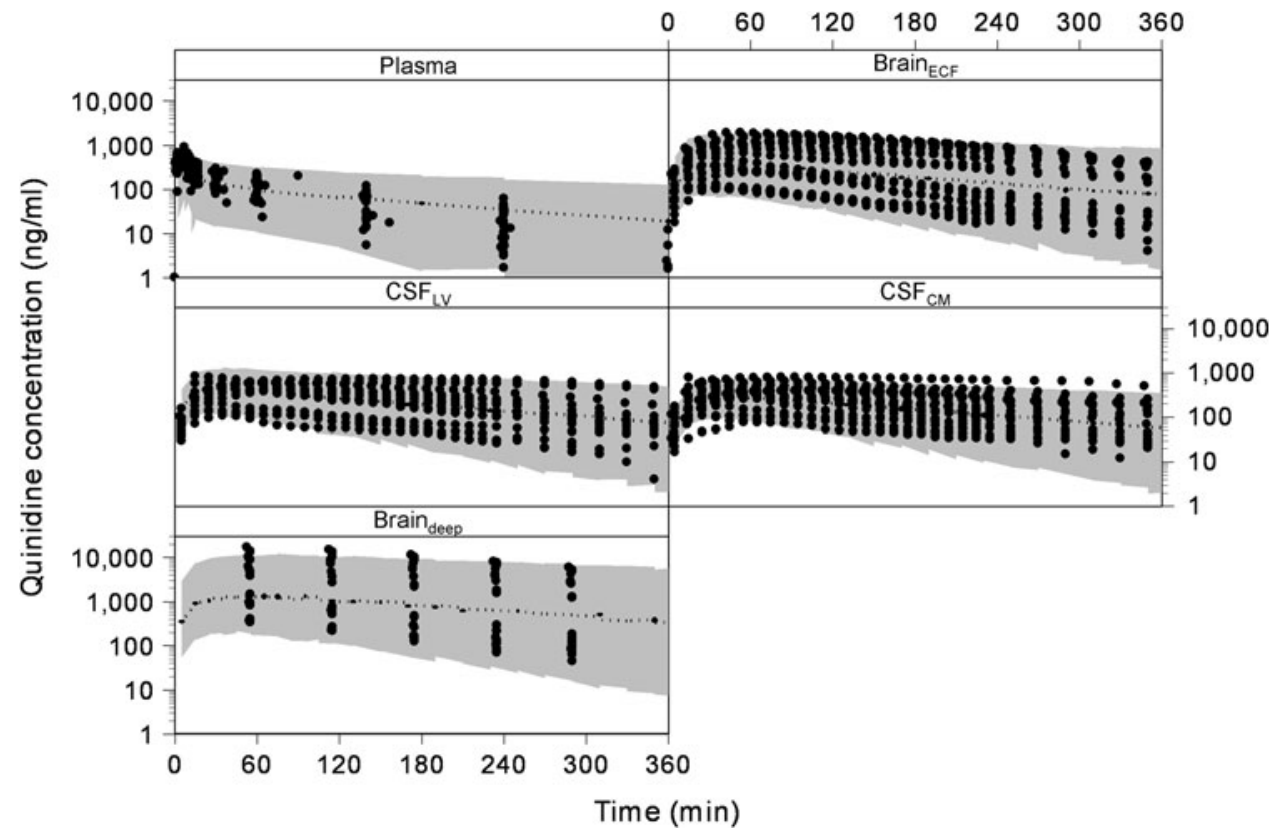

in vivo situation, like ours. Giacomini et al. [65] stated that quinidine is a potential inhibitor of OCTs. OCTs have been localized both at the BBB [66], as well as at the BCSFB [67]. Thus, the possibility of active influx transport for quinidine at the $\mathrm{BBB}$ and $\mathrm{BCSFB}$ remains to be further investigated. Alternatively, it could reflect a passive "iontrapping" process, governed by lower $\mathrm{pH}$ values in brain ECF ( $\mathrm{pH} \sim 7.3$ ) than in plasma ( $\mathrm{pH} \sim 7.4$ ). However, as quinidine is a diprotic base with pKas 4.2 and 7.9 [30], the low difference between the \% ionized at $\mathrm{pH} 7.3(80 \%)$ and $\mathrm{pH} 7.4(76 \%)$ does not seem to explain our findings.

According to the "smaller than threefold concentration ratio paradigm" [7], differences between brain ECF $_{\text {and CSF }}$ concentrations of quinidine as found in this study (on average $0.72 \pm 0.20$ ) would be considered pharmacokinetically irrelevant. However, upon co-administration of tariquidar this ratio increased 3.1-fold (to the value of $2.22 \pm 0.57)$. This means that P-gp functionality and variations thereof may have an important effect on the brai$\mathrm{n}_{\mathrm{ECF}}-\mathrm{CSF}$ ratio and the extrapolation from rats to humans, as is discussed by de Lange [68, 69]. However, quinidine is a strong P-gp substrate and it remains to be investigated what the impact of P-gp functionality on the brain ECF $_{-C S F}$ concentration relationships would be for weaker substrates.

Several different models for P-gp-mediated transport have been suggested. [28, 51, 56, 57, 70-72]. The first model is described as the "classical pump model" in which a P-gp substrate is transported from the cytosol to the extracellular space against a concentration gradient (so-called "efflux enhancement"). [51, 56, 70-72] The second model can be described as a "vacuum cleaner model" in which a lipophilic compound that is diffusing across the cellular membrane, is interacting with P-gp within the lipid bilayer of the cellular membrane and is then transported back into the extracellular space. [28, 70-72] The third model is described as the "flippase model" in which a lipophilic compound within the lipid bilayer at the cytosolic side is flipped to the extracellular side where it diffuses back into the extracellular space. [51, 56, 57, 70-72] In the second and third model P-gp prevents the entry of compounds to the brain by a process which is called "influx hindrance". Based on the SBPK modeling results, it appears that for quinidine P-gp acts via combined influx hindrance and efflux enhancement. This is in line with the localization of P-gp at both the luminal and abluminal membrane of the BBB [21].

For the potential role of $\mathrm{P}-\mathrm{gp}$ at the BCSFB, there have been some indications that $\mathrm{P}$-gp could function as an influx transporter at the BCSFB [22, 27]. We anticipated this to be among our findings, however, with our data we could not identify P-gp influx at the level of the BCSFB. Instead, the results of the SBPK modelling suggest that P-gp at the BCSFB functions as an efflux transporter (LV) or is not functioning at all (CM).

Then, interestingly, the co-administration of tariquidar results in an increase of the total brain-to-brain ${ }_{\mathrm{ECF}}$ concentration ratio, which has also been observed in an earlier study on quinidine at our lab by Syvänen et al. [32]. This indicates that P-gp is also located beyond the BBB at the parenchymal and perivascular astrocytes, which is in line with several reports [73-78].

In our current study we obtained in parallel brain ST, CSF and plasma concentration-time profiles, under dynamic conditions, included corrections for in vivo probe recoveries, and plasma protein binding to finally obtain unbound concentrations in these body compartments. It is anticipated that this approach, combined with advanced mathematical modelling, 
will further improve revealing the mechanisms underlying the

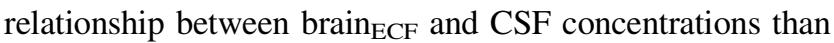
will steady-state and/or single end-of-experiment CSF concentrations [79]. Having information on concentration-time profiles following a single administration is relevant as we need time-dependent data to decipher the rate and extent of processes of drug transport into, within, and out of the brain [80]. It provides the best basis to further explore the multiple dose regimens as used in the clinic, for which it is know that a true steady state condition is actually not reached.

Finally, in striving towards reduction on the use of animals on one hand, and the fact that systematic studies on the inter-relationship of plasma $\mathrm{PK}, \mathrm{BBB}$ transport and intra-brain distribution, cannot be performed in human, the use of the multiple microdialysis probe approach [20], obtaining a total of 84 samples per animal, results in a great reduction in the number of animals required for these type of studies compared to the single time point measurements.

\section{Conclusion}

It is concluded that in parallel obtained data on unbound brain $_{\mathrm{ECF}}, \mathrm{CSF}$ and plasma concentrations, under dynamic conditions, combined with advanced mathematical modelling is a most valid approach to reveal the mechanisms underlying the relationship between brain ${ }_{\mathrm{ECF}}$ and CSF concentrations, which is significantly influenced by activity of $\mathrm{P}$-gp. This indicates that information on functionality of P-gp is important for the prediction of human brain target site concentrations of P-gp substrates on the basis of human CSF concentrations, and provides further guide to unravelling mechanisms and drug properties that govern the transport into, within, and out of the brain, for translational purposes.

Acknowledgments The authors would like to thank Dirk-Jan van den Berg and Robin Hartman for their help and guidance with the surgical procedure, experimental set-up and the plasma, microdialysate and total brain sample concentration analysis. This work was supported by Top Institute Pharma, Project T5-105-1: Nanoscience as a tool for improving bioavailability and BBB penetration.

Open Access This article is distributed under the terms of the Creative Commons Attribution License which permits any use, distribution, and reproduction in any medium, provided the original author(s) and the source are credited.

\section{Appendix}

Differential equations

The mass balance equations describing the final SBPK model were expressed as follows.
Plasma:

$$
\begin{aligned}
d A_{p l, u} / d t= & d o s e-k_{P L-P E R 1} A_{p l, u}+k_{P E R 1-P L} A_{P E R 1} \\
& -k_{P L-P E R 2} A_{p l, u}+k_{P E R 2-P L} A_{P E R 2} \\
& -k_{P L-D B R} A_{p l, u}+k_{D B R-P L} A_{D B R}-k_{P L-E C F} A_{p l, u} \\
& +k_{E C F-P L} A_{E C F}-k_{P L-L V} A_{p l, u}+k_{L V-P L} A_{L V} \\
& -k_{P L-T F V} A_{p l, u}+k_{T F V-P L} A_{T F V}-k_{P L-C M} A_{p l, u} \\
& +k_{C M-P L} A_{C M}+\left(Q_{C S F} / V_{S A S}\right) A_{S A S}-k_{E} A_{P L, u}
\end{aligned}
$$

$C_{P L, u}=A_{P L, u} / V_{P L}$

Periphery:

$d A_{P E R 1} / d t=k_{P L-P E R 1} A_{P L, u}-k_{P E R 1-P L} A_{P E R 1}$

$C_{P E R 1}=A_{P E R 1} / V_{P E R 1}$

$d A_{P E R 2} / d t=k_{P L-P E R 2} A_{P L, u}-k_{P E R 2-P L} A_{P E R 2}$

$C_{P E R 2}=A_{P E R 2} / V_{P E R 2}$

Brain $_{\text {deep }}$ :

$d A_{D B R} / d t=k_{P L-D B R} A_{P L, u}-k_{D B R-P L} A_{D B R}$

$C_{D B R}=A_{D B R} / V_{D B R}$

Brain $_{\mathrm{ECF}}$ :

$d A_{E C F} / d t=k_{P L-E C F} A_{P L, u}-k_{E C F-P L} A_{E C F}$ - $\left(Q_{E C F} / V_{E C F}\right) A_{E C F}$

$C_{E C F}=A_{E C F} / V_{E C F}$

$\mathrm{CSF}_{\mathrm{LV}}$ :

$d A_{L V} / d t=k_{P L-L V} A_{P L, u}-k_{L V-P L} A_{L V}+\left(Q_{E C F} / V_{E C F}\right) A_{E C F}$ $-\left(Q_{C S F} / V_{L V}\right) A_{L V}$

$C_{L V}=A_{L V} / V_{L V}$

$\mathrm{CSF}_{\mathrm{TFV}}$ :

$d A_{T F V} / d t=k_{P L-T F V} A_{P L, u}-k_{T F V-P L} A_{T F V}$ $+\left(Q_{C S F} / V_{L V}\right) A_{L V}-\left(Q_{C S F} / V_{T F V}\right) A_{T F V}$

$C_{T F V}=A_{T F V} / V_{T F V}$

$\mathrm{CSF}_{\mathrm{CM}}$ :

$d A_{C M} / d t=k_{P L-C M} A_{P L, u}-k_{C M-P L} A_{C M}$ $+\left(Q_{C S F} / V_{T F V}\right) A_{T F V}-\left(Q_{C S F} / V_{C M}\right) A_{C M}$

$C_{C M}=A_{C M} / V_{C M}$

$\mathrm{CSF}_{\mathrm{SAS}}$ :

$d A_{S A S} / d t=\left(Q_{C S F} / V_{C M}\right) A_{C M}-\left(Q_{C S F} / V_{S A S}\right) A_{S A S}$

$C_{S A S}=A_{S A S} / V_{S A S}$

where $\quad k_{E}=\left(C L_{E, p}+C L_{E, P-g p}\right) / V_{P L}$;

$k_{P L-P E R 1}=Q_{P L-P E R 1} / V_{P L} ; \quad k_{P E R 1-P L}=Q_{P L-P E R 1} / V_{P E R 1} ;$

$k_{P L-P E R 2}=Q_{P L-P E R 2} / V_{P L} ; \quad k_{P E R 2-P L}=Q_{P L-P E R 2} / V_{P E R 2} ;$

$k_{P L-D B R}=\left(C L_{P L-D B R, p}-C L_{P L-D B R, P-g p}\right) / V_{P L}$; 
$k_{D B R-P L}=\left(C L_{D B R-P L, p}+C L_{D B R-P L, P-g p}\right) / V_{D B R} ;$

$k_{P L-E C F}=\left(C L_{P L-E C F, p}-C L_{P L-E C F, P-g p}\right) / V_{P L}$;

$k_{E C F-P L}=\left(C L_{E C F-P L, p}+C L_{E C F-P L, P-g p}\right) / V_{E C F}$;

$k_{P L-L V}=\left(C L_{P L-L V, p}-C L_{P L-L V, P-g p}\right) / V_{P L}$

$k_{L V-P L}=\left(C L_{L V-P L, p}+C L_{L V-P L, P-g p}\right) / V_{L V}$

$k_{P L-T F V}=\left(C L_{P L-T F V, p}-C L_{P L-T F V, P-g p}\right) / V_{P L}$

$k_{T F V-P L}=\left(C L_{T F V-P L, p}+C L_{T F V-P L, P-g p}\right) / V_{T F V} ;$

$k_{P L-C M}=\left(C L_{P L-C M, p}-C L_{P L-C M, P-g p}\right) / V_{P L}$;

and

$k_{C M-P L}=\left(C L_{C M-P L, p}+C L_{C M-P L, P-g p}\right) / V_{C M}$

\section{References}

1. De Lange ECM, de Boer AG, Breimer DD (2000) Methodological issues in microdialysis sampling for pharmacokinetic studies. Adv Drug Del Rev 45:125-148

2. Hammarlund-Udenaes M (2009) Active-site concentrations of chemicals-are they a better predictor of effect than plasma/ organ/tissue concentrations? Basic Clin Pharmacol Toxicol 106:215-220

3. De Lange ECM, Danhof M, de Boer AG, Breimer DD (1997) Methodological considerations of intracerebral microdialysis in pharmacokinetic studies on drug transport across the blood-brain barrier. Brain Res Rev 25:27-49

4. Hammarlund-Udenaes M, Bredberg U, Fridén M (2009) Methodologies to assess brain drug delivery in lead optimization. Curr Top Med Chem 9:148-162

5. Westerhout J, Danhof M, de Lange ECM (2011) Preclinical prediction of human brain target site concentrations: considerations in extrapolating to the clinical setting. J Pharm Sci 100:3577-3593

6. Kalvass JC, Maurer TS (2002) Influence of nonspecific brain and plasma binding of CNS exposure: implications for rational drug discovery. Biopharm Drug Dispos 23:327-338

7. Maurer TS, DeBartolo DB, Tess DA, Scott D (2005) Relationship between exposure and nonspecific binding of thirty-three central nervous system drugs in mice. Drug Metab Dispos 33:175-181

8. Liu X, Smith BJ, Chen C, Callegari E, Becker SL, Chen X, Cianfrogna J, Doran AC, Doran SD, Gibbs JP, Hosea N, Liu J, Nelson FR, Szewc MA, Van Deusen J (2006) Evaluation of cerebrospinal fluid concentration and plasma free concentration as a surrogate measurement for brain free concentration. Drug Metab Dispos 34:1443-1447

9. Liu X, Van Natta K, Yeo H, Vilenski O, Weller PE, Worboys PD, Monshouwer M (2009) Unbound drug concentration in brain homogenate and cerebral spinal fluid at steady state as a surrogate for unbound concentration in brain interstitial fluid. Drug Metab Dispos 37:787-793

10. Fridén $M$, Winiwarter $S$, Jerndal $G$, Bengtsson $O$, Wan $H$, Bredberg U, Hammarlund-Udenaes M, Antonsson M (2009) Structure-brain exposure relationships in rat and human using a novel data set of unbound drug concentrations in brain interstitial and cerebrospinal fluids. J Med Chem 52:6233-6243

11. Lee G, Dallas S, Hong M, Bendayan R (2001) Drug transporters in the central nervous system: brain barriers and brain parenchyma considerations. Pharmacol Rev 53:569-596

12. De Lange ECM, Danhof M (2002) Considerations in the use of cerebrospinal fluid pharmacokinetic to predict brain target concentrations in the clinical setting. Implications of the barriers between blood and brain. Clin Pharmacokinet 41:691-703
13. Shen DD, Artru AA, Adkison KK (2004) Principles and applicability of CSF sampling for the assessment of CNS drug delivery and pharmacodynamics. Adv Drug Del Rev 56:1825-1857

14. Lin JH (2008) CSF as a surrogate for assessing CNS exposure: an industrial perspective. Curr Drug Metab 9:46-59

15. Mayer S, Maickel RP, Brodie BB (1959) Kinetics of penetration of drugs and other foreign compounds into cerebrospinal fluid and brain. J Pharmacol Exp Ther 127:205-211

16. Oldendorf WH (1974) Lipid solubility and drug penetration of the blood-brain barrier. Proc Soc Exp Biol Med 147:813-815

17. Betz AL, Goldstein GW (1986) Specialized properties and solute transport in brain capillaries. Annu Rev Physiol 48:241-250

18. Keep RF, Jones HC (1990) A morphometric study on the development of the lateral ventricle choroid plexus, choroid plexus capillaries and ventricular ependyma in the rat. Dev Brain Res 56:47-53

19. Danhof M, de Jongh J, de Lange ECM, Della Pasqua OE, Ploeger BA, Voskuyl RA (2007) Mechanism-based pharmacokineticpharmacodynamic modeling: biophase distribution, receptor theory, and dynamical systems analysis. Annu Rev Pharmacol Toxicol 47:357-400

20. Westerhout J, Ploeger B, Smeets J, Danhof M, de Lange ECM (2012) Physiologically based pharmacokinetic modeling to investigate regional brain distribution kinetics in rats. AAPS J 14:543-553

21. Bendayan R, Ronaldson PT, Gingras D, Bendayan M (2006) In situ localization of P-glycoprotein (ABCB1) in human and rat brain. J Histochem Cytochem 54:1159-1167

22. Rao VV, Dahlheimer JL, Bardgett ME, Snyder AZ, Finch RA, Sartorelli AC, Piwnica-Worms D (1999) Choroid plexus epithelial expression of MDR1 P-glycoprotein and multidrug resistanceassociated protein contribute to the blood-cerebrospinal-fluid drug-permeability barrier. Proc Natl Acad Sci USA 96:3900-3905

23. Schinkel AH, Smit JJM, van Tellingen O, Beijnen JH, Wagenaar E, van Deemter L, Mol CAAM, van der Valk MA, RobanusMaandag EC, te Riele HPJ, Berns AJM, Borst P (1994) Disruption of the mouse mdrla P-glycoprotein gene leads to a deficiency in the blood-brain barrier and to increased sensitivity to drugs. Cell 77:491-502

24. Schinkel AH, Mayer U, Wagenaar E, Mol CAAM, van Deemter L, Smit JJM, van der Valk MA, Voordouw AC, Spits H, van Tellingen O, Zijlmans JM, Fibbe WE, Borst P (1997) Normal viability and altered pharmacogenetics in mice lacking mdr1-type (drug-transporting) P-glycoproteins. Proc Natl Acad USA 94: 4028-4033

25. Schinkel AH (1999) P-glycoprotein, a gatekeeper in the bloodbrain barrier. Adv Drug Del Rev 36:179-194

26. Wijnholds J, de Lange ECM, Scheffer GL, van den Berg D-J, Mol CAAM, van der Valk M, Schinkel AH, Scheper RJ, Breimer DD, Borst P (2000) Multidrug resistance protein 1 protects the choroid plexus epithelium and contributes to the blood-cerebrospinal fluid barrier. J Clin Invest 105:279-285

27. Kassem NA, Deane R, Segal MB, Chen RL, Preston JE (2007) Thyroxine $\left(\mathrm{T}_{4}\right)$ transfer from CSF to choroid plexus and ventricular brain regions in rabbit: contributory role of P-glycoprotein and organic anion transporting polypeptides. Brain Res 1181:44-50

28. Kusuhara H, Suzuki H, Terasaki T, Kakee A, Lemaire M, Sugiyama Y (1997) P-glycoprotein mediates the efflux of quinidine across the blood-brain barrier. J Pharmacol Exp Ther 283: 574-580

29. Doran A, Obach RS, Smith BJ, Hosea NA, Becker S, Callegari E, Chen C, Chen X, Choo E, Cianfrogna J, Cox LM, Gibbs JP, Gibbs MA, Hatch H, Hop CECA, Kasman IN, LaPerle J, Liu JH, Liu X, Logman M, Maclin D, Nedza FM, Nelson F, Olson E, Rahematpura S, Raunig D, Rogers S, Schmidt K, Spracklin DK, Szewc M, Troutman M, Tseng E, Tu M, Van Deusen JW, 
Venkatakrishnan K, Walens G, Wang EQ, Wong D, Yasgar AS, Zhang C (2005) The impact of P-glycoprotein on the disposition of drugs targeted for indications of the central nervous system: evaluation using the mdr1a/1b knockout mouse model. Drug Metab Dispos 33:165-174

30. Varma MVS, Panchagnula R (2005) pH-dependent functional activity of P-glycoprotein in limiting intestinal absorption of protic drugs: kinetic analysis of quinidine efflux in situ. J Pharm Sci 94:2632-2643

31. Sziráki I, Erdo F, Beéry E, Molnar PM, Fazakas C, Wilhelm I, Makai I, Kis E, Herédi-Szabó K, Abonyi T, Krizbai I, Tóth GK, Krajcsi P (2011) Quinidine as an ABCB1 probe for testing drug interactions at the blood-brain barrier: an in vitro in vivo correlation study. J Biomol Screen 16:886-894

32. Syvänen S, Schenke M, van den Berg D-J, Voskuyl RA, de Lange ECM (2012) Alteration in P-glycoprotein functionality affects intrabrain distribution of quinidine more than brain entry-a study in rats subjected to status epilepticus by kainate. AAPS J 14:87-96

33. Fox E, Bates SE (2007) Tariquidar (XR9576): a P-glycoprotein drug efflux pump inhibitor. Expert Rev Anticancer Ther 7: 447-459

34. Kurnik D, Sofowora GG, Donahue JP, Nair UB, Wilkinson GR, Wood AJJ, Muszkat M (2008) Tariquidar, a selective P-glycoprotein inhibitor, does not potentiate loperamide's opioid brain effects in humans despite full inhibition of lymphocyte P-glycoprotein. Anesthesiology 109:1092-1099

35. Ståhle L, Segersvärd S, Ungerstedt U (1991) A comparison between three methods for estimation of extracellular concentrations of exogenous and endogenous compounds by microdialysis. J Pharmacol Methods 25:41-52

36. Scheller D, Kolb J (1991) The internal reference technique in microdialysis: a practical approach to monitoring dialysis efficiency and to calculating tissue concentration from dialysate samples. J Neurosci Methods 40:31-38

37. Harashima H, Sawada Y, Sugiyama Y, Iga T, Hanano M (1985) Analysis of nonlinear tissue distribution of quinidine in rats by physiologically based pharmacokinetics. J Pharmacokinet Biopharm 13:425-440

38. Thorne RG, Hrabĕtová S, Nicholson C (2004) Diffusion of epidermal growth factor in rat brain extracellular space measured by integrative optical imaging. J Neurophysiol 92:3471-3481

39. Cserr HF, Cooper DN, Suri PK, Patlak CS (1981) Efflux of radiolabeled polyethylene glycols and albumin from rat brain. Am J Physiol 240:F319-F328

40. Bass NH, Lundborg P (1973) Postnatal development of bulk flow in the cerebrospinal fluid system of the albino rat: clearance of carboxyl-[14C]inulin after intrathecal infusion. Brain Res 52: 323-332

41. Condon P, Patterson J, Wyper D, Hadley D, Grant R, Teasdale G, Rowan J (1986) Use of magnetic resonance imaging to measure intracranial cerebrospinal fluid volume. Lancet 327:1355-1357

42. Kohn MI, Tanna NK, Herman GT, Resnick SM, Mozley PD, Gur RE, Alavi A, Zimmerman RA, Gur RC (1991) Analysis of brain and cerebrospinal fluid volumes with MR imaging. Part I. Methods, reliability, and validation. Radiology 178:115-122

43. Levinger IM (1971) The cerebral ventricles of the rat. J Anat 108:447-451

44. Robertson EG (1949) Developmental defects of the cisterna magna and dura mater. J Neurol Neurosurg Psychiatry 12:39-51

45. Adam R, Greenberg JO (1978) The mega cisterna magna. J Neurosurg 48:190-192

46. Abbott NJ (2004) Evidence for bulk flow of brain interstitial fluid: significance for physiology and pathology. Neurochem Int 45:545-552

47. Cserr HF (1965) Potassium exchange between cerebrospinal fluid, plasma, and brain. Am J Physiol 209:1219-1226
48. Cox EH, Veyrat-Follet C, Beal SL, Fuseau E, Kenkare S, Sheiner LB (1999) A population pharmacokinetic-pharmacodynamic analysis of repeated measures time-to-event pharmacodynamic responses: the antiemetic effect of ondansetron. J Pharmacokinet Biopharm 27:625-644

49. Duffull SB, Aarons L (2000) Development of a sequential linked pharmacokinetic and pharmacodynamic simulation model for ivabradine in healthy volunteers. Eur J Pharm Sci 10:275-284

50. Yano Y, Beal SL, Sheiner LB (2001) Evaluating pharmacokinetic/pharmacodynamic models using the posterior predictive check. J Pharmacokinet Pharmacodyn 28:171-192

51. Syvänen S, Xie R, Sahin S, Hammarlund-Udenaes M (2006) Pharmacokinetic consequences of active drug efflux at the bloodbrain barrier. Pharm Res 23:705-717

52. Lee HB, Blaufox MD (1985) Blood volume in the rat. J Nucl Med 26:72-76

53. Ball WJ Jr, Tse-Eng D, Wallick ET, Bilezikian JP, Schwartz A, Butler VP (1981) Effect of quinidine on the digoxin receptor in vitro. J Clin Invest 68:1065-1074

54. Ernst SA, Palacios JR 2nd, Siegel GJ (1986) Immunocytochemical localization of $\mathrm{Na}^{+}, \mathrm{K}^{+}$-ATPase catalytic polypeptide in mouse choroid plexus. J Histochem Cytochem 34:189-195

55. Brown PD, Davies SL, Speake T, Millar ID (2004) Molecular mechanisms of cerebrospinal fluid production. Neuroscience 129:957-970

56. Stein WD, Cardarelli C, Pastan I, Gottesman MM (1994) Kinetic evidence suggesting that the multidrug transporter differentially handles influx and efflux of its substrates. Mol Pharmacol 45:763-772

57. Sun H, Bungay PM, Elmquist WF (2001) Effect of capillary efflux transport inhibition on the determination of probe recovery during in vivo microdialysis in the brain. J Pharmacol Exp Ther 297:991-1000

58. Machatha SG, Yalkowsky SH (2005) Comparison of the octanol/ water partition coefficients calculated by $C \log \mathrm{P}^{\circledR}, \mathrm{ACD} \log \mathrm{P}$ and KowWin ${ }^{\circledR}$ to experimentally determined values. Int J Pharm 294:185-192

59. Mistry P, Stewart AJ, Dangerfield W, Okiji S, Liddle C, Bootle D, Plumb JA, Templeton D, Charlton P (2001) In vitro and in vivo reversal of P-glycoprotein-mediated multidrug resistance by a novel potent modulator, XR9576. Cancer Res 61:749-758

60. Bankstahl JP, Kuntner C, Abrahim A, Karch R, Stanek J, Wanek T, Wadsak W, Kletter K, Müller M, Löscher W, Langer O (2008) Tariquidar-induced P-glycoprotein inhibition at the rat bloodbrain barrier studied with (R)- ${ }^{11} \mathrm{C}$-Verapamil and PET. J Nucl Med 49:1328-1335

61. Syvänen S, Luurtsema G, Molthoff CFM, Windhorst AD, Huisman MC, Lammertsma AA, Voskuyl RA, de Lange ECM (2011) (R)- $\left[{ }^{11} \mathrm{C}\right]$ Verapamil PET studies to assess changes in P-glycoprotein expression and functionality in rat blood-brain barrier after exposure to kainate-induced status epilepticus. BMC Med Imaging. doi:10.1186/1471-2342-11-1

62. Kakee A, Terasaki T, Sugiyama Y (1996) Brain efflux index as a novel method of analyzing efflux transport at the blood-brain barrier. J Pharmacol Exp Ther 277:1550-1559

63. Kodaira H, Kusuhara H, Fujita T, Ushiki J, Fuse E, Sugiyama Y (2011) Quantitative evaluation of the impact of active efflux by P-glycoprotein and breast cancer resistance protein at the bloodbrain barrier on the predictability of the unbound concentrations of drugs in the brain using cerebrospinal fluid concentrations as a surrogate. J Pharmacol Exp Ther 339:935-944

64. Van Montfoort JE, Müller M, Groothuis GMM, Meijer DKF, Koepsell H, Meier PJ (2001) Comparison of "type I" and "type II" organic cation transport by organic cation transporters and organic anion-transporting polypeptides. J Pharmacol Exp Ther 298:110-115 
65. Giacomini KM, Huang S-M, Tweedie DJ, Benet LZ, Brouwer KLR, Chu X, Dahlin A, Evers R, Fischer V, Hillgren KM, Hoffmaster KA, Ishikawa T, Keppler D, Kim RB, Lee CA, Niemi M, Polli JW, Sugiyama Y, Swaan PW, Ware JA, Wright SH, Wah Yee S, Zamek-Gliszczyncski MJ, Zhang L (2010) Membrane transporters in drug development. Nat Rev Drug Discov 9:215-236

66. Lin C-J, Tai Y, Huang M-T, Tsai Y-F, Hsu H-J, Tzen K-Y, Liou $\mathrm{H}-\mathrm{H}$ (2010) Cellular localization of the organic cation transporters, OCT1 and OCT2, in brain microvessel endothelial cells and its implication for MPTP transport across the blood-brain barrier and MPTP-induced dopaminergic toxicity in rodents. J Neurochem 114:717-727

67. Choudhuri S, Cherrington NJ, Li N, Klaassen CD (2003) Constitutive expression of various xenobiotic and endobiotic transporter mRNAs in the choroid plexus of rats. Drug Metab Dispos 31:1337-1345

68. De Lange ECM (2013) Utility of CSF in translational neuroscience. J Pharmacokinet Pharmacodyn. doi:10.1007/s10928-013-9301-9

69. De Lange ECM (2013) The mastermind approach to CNS drug therapy: translational prediction of human brain distribution, target site kinetics, and therapeutic effects. Fluids and barriers of the CNS, theme issue "Technique and Research Protocols to study Brain Barriers in Vivo, in Vitro and in Situ". Ed B. Engelhardt, D. Stamirovic, and EC de Lange. Fluids Barriers CNS 10:12. doi:10.1186/2045-8118-10-12

70. Higgins CF, Gottesman MM (1992) Is the multidrug transporter a flippase? Trends Biochem Sci 17:18-21

71. Sharom FJ (1997) The P-glycoprotein efflux pump: how does it transport drugs? J Membr Biol 160:161-175

72. Sharom FJ (2006) Shedding light on drug transport: structure and function of the P-glycoprotein multidrug transporter (ABCB1). Biochem Cell Biol 84:979-992
73. Pardridge WM, Golden PL, Kang YS, Bickel U (1997) Brain microvascular and astrocyte localization of P-glycoprotein. J Neurochem 68:1278-1285

74. Declèves X, Regina A, Laplanche JL, Roux F, Boval B, Launay JM, Scherrmann JM (2000) Functional expression of P-glycoprotein and multidrug resistance-associated protein (Mrp1) in primary cultures of rat astrocytes. J Neurosci Res 60:594-602

75. Golden PL, Pardridge WM (2000) Brain microvascular P-glycoprotein and a revised model of multidrug resistance in brain. Cell Mol Neurobiol 20:165-181

76. Seegers U, Potschka H, Löscher W (2002) Transient increase of P-glycoprotein expression in endothelium and parenchyma of limbic brain regions in the kainate model of temporal lobe epilepsy. Epilepsy Res 51:257-268

77. Seegers U, Potschka H, Löscher W (2002) Expression of the multidrug transporter P-glycoprotein in brain capillary endothelial cells and brain parenchyma of amygdala-kindled rats. Epilepsia 43:675-684

78. Volk HA, Potschka H, Löscher W (2005) Immunohistochemical localization of P-glycoprotein in rat brain and detection of its increased expression by seizures are sensitive to fixation and staining variables. J Histochem Cytochem 53:517-531

79. Kielbasa W, Kalvass JC, Stratford R (2009) Microdialysis evaluation of atomoxetine brain penetration and central nervous system pharmacokinetics in rats. Drug Metab Dispos 37:137-142

80. Hammarlund-Udenaes M, Fridén M, Syvänen S, Gupta A (2008) On the rate and extent of drug delivery to the brain. Pharm Res 25:1737-1750 